\title{
Large-Scale Green Synthesis of Porphyrins
}

Sruti Mondal, Tanmoy Pain, Kasturi Sahu, and Sanjib Kar*

School of Chemical Sciences, National Institute of Science Education and Research (NISER), Bhubaneswar - 752050, India, and Homi Bhabha National Institute, Training School Complex, Anushakti Nagar, Mumbai, 400 094, India.

E-mail: sanjib@niser.ac.in 
Figure S1 $\quad{ }^{1} \mathrm{H}$ NMR spectrum of 5,10,15,20-Tetraphenylporphyrin, 1 in $\mathrm{CDCl}_{3}$.

Figure S2 $\quad{ }^{1} \mathrm{H}$ NMR spectrum of 5,10,15,20-Tetrakis(4-methoxyphenyl)porphyrin, 2 in $\mathrm{CDCl}_{3}$.

Figure S3 $\quad{ }^{1} \mathrm{H}$ NMR spectrum of 5,10,15,20-Tetrakis(4-nitrophenyl)porphyrin, 3 in $\mathrm{CDCl}_{3}$.

Figure S4 $\quad{ }^{1} \mathrm{H}$ NMR spectrum of 5,10,15,20-Tetrakis(4-chlorophenyl)porphyrin, 4 in $\mathrm{CDCl}_{3}$.

Figure S5 $\quad{ }^{1} \mathrm{H}$ NMR spectrum of 5,10,15,20-Tetrakis(4-methylphenyl)porphyrin, 5 in $\mathrm{CDCl}_{3}$.

Figure S6 $\quad{ }^{1} \mathrm{H}$ NMR spectrum of 5,10,15,20-Tetrakis(2,4,6-trimethylphenyl)porphyrin, 6 in $\mathrm{CDCl}_{3}$.

Figure S7 $\quad{ }^{1} \mathrm{H} \quad \mathrm{NMR}$ spectrum of 5,10,15,20-Tetrakis-(4-ethylphenyl)porphyrin, 7 in $\mathrm{CDCl}_{3}$.

Figure S8 $\quad{ }^{1} \mathrm{H}$ NMR spectrum of 5,10,15,20-Tetrakis(4-cyanophenyl)porphyrin, $\mathbf{8}$ in $\mathrm{CDCl}_{3}$.

Figure S9 $\quad{ }^{1} \mathrm{H}$ NMR spectrum of 5,10,15,20-Tetrakis(4-iodophenyl)porphyrin, 9 in $\mathrm{CDCl}_{3}$.

Figure S10 $\quad{ }^{1} \mathrm{H}$ NMR spectrum of 5,10,15,20-Tetrakis(4-bromophenyl)porphyrin, 10 in $\mathrm{CDCl}_{3}$.

Figure S11 ${ }^{1} \mathrm{H}$ NMR spectrum of 5,10,15,20-Tetrakis(3-bromophenyl)porphyrin, 11 in $\mathrm{CDCl}_{3}$.

Figure S12 $\quad{ }^{1} \mathrm{H}$ NMR spectrum of 5,10,15,20-(tetra-4-trifluoromethylphenyl)porphyrin, 12 in $\mathrm{CDCl}_{3}$.

Figure S13 ${ }^{1} \mathrm{H}$ NMR spectrum of 5,10,15,20-Tetrakis(4-butoxyphenyl)porphyrin, 13 in $\mathrm{CDCl}_{3}$.

Figure S14 ${ }^{1} \mathrm{H}$ NMR spectrum of 5,10,15,20-Tetrakis[4-(benzyloxy)phenyl]porphyrin, 14 in $\mathrm{CD}_{2} \mathrm{Cl}_{2}$.

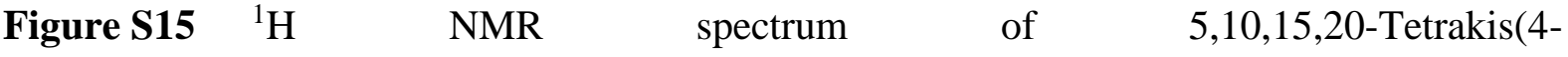
methoxycarbonylphenyl)porphyrin, 15 in $\mathrm{CDCl}_{3}$.

Figure S16 $\quad{ }^{1} \mathrm{H} \quad$ NMR $\quad$ spectrum of $5,10,15,20$-Tetrakis(4,7-dimethoxynaphthalen-1yl)porphyrin, 16 in $\mathrm{CDCl}_{3}$.

Figure S17 $\quad{ }^{13} \mathrm{C}\left\{{ }^{1} \mathrm{H}\right\} \mathrm{NMR} \quad(101 \quad \mathrm{MHz})$ spectrum of $5,10,15,20-$ Tetrakis(4,7-dimethoxynaphthalen-1-yl)porphyrin, 16 in $\mathrm{CDCl}_{3}$.

Figure S18 $\quad{ }^{1} \mathrm{H} \quad$ NMR $\quad$ spectrum of $\quad$ 5,15-Bis(4-bromophenyl)-10,20-bis(4nitrophenyl)porphyrin, 21 in $\mathrm{CDCl}_{3}$. 
Figure S19 $\quad{ }^{1} \mathrm{H}$ NMR spectrum of 5,15-Bis(4-nitrophenyl)-10,20-diphenylporphyrin, 22 in $\mathrm{CDCl}_{3}$.

Figure S20 $\quad{ }^{1} \mathrm{H} \quad$ NMR spectrum of 5,15-Bis(4-methoxyphenyl)-10,20-bis(4nitrophenyl)porphyrin, 23 in $\mathrm{CDCl}_{3}$.

Figure S21 $\quad{ }^{1} \mathrm{H} \quad$ NMR $\quad$ spectrum of $\quad$ 5,15-bis(4-cyanophenyl)-10,20-bis(4nitrophenyl)porphyrin, 24 in $\mathrm{CDCl}_{3}$.

Figure S22 ${ }^{13} \mathrm{C}\left\{{ }^{1} \mathrm{H}\right\}$ NMR (101 MHz) spectrum of 5,15-bis(4-cyanophenyl)-10,20-bis(4nitrophenyl)porphyrin, 24 in $\mathrm{CDCl}_{3}$.

Figure S23 $\quad{ }^{1} \mathrm{H} \quad$ NMR $\quad$ spectrum of $\quad$ 5,15-Bis(4-methoxyphenyl)-10,20-(4chlorophenyl)porphyrin, 25 in $\mathrm{CDCl}_{3}$.

Figure S24 ${ }^{1} \mathrm{H}$ NMR spectrum of 5,15-Bis(4-cyanophenyl)-10,20-diphenylporphyrin, 26 in $\mathrm{CDCl}_{3}$.

Figure S25 $\quad{ }^{1} \mathrm{H} \quad$ NMR $\quad$ spectrum of $\quad$ 5,15-Bis(4-bromophenyl)-10,20-(4methylphenyl)porphyrin, 27 in $\mathrm{CDCl}_{3}$.

Figure S26 $\quad{ }^{1} \mathrm{H} \quad$ NMR $\quad$ spectrum of 5,15-bis(4-cyanophenyl)-10,20-bis(4methoxyphenyl)porphyrin, 28 in $\mathrm{CDCl}_{3}$.

Figure S27 $\quad{ }^{1} \mathrm{H}$ NMR spectrum of 5,15-Bis(4-methylphenyl)-10,20-diphenylporphyrin, 29 in $\mathrm{CDCl}_{3}$.

Figure S28 $\quad{ }^{1} \mathrm{H} \quad$ NMR $\quad$ spectrum of $\quad$ 5,15-Bis(4-methoxyphenyl)-10,20-(4methylphenyl)porphyrin, 30 in $\mathrm{CDCl}_{3}$.

Figure S29 $\quad{ }^{1} \mathrm{H}$ NMR spectrum of 5,15-Bis(4-methoxyphenyl)-10,20-diphenylporphyrin, 31 in $\mathrm{CDCl}_{3}$.

Figure S30 $\quad{ }^{1} \mathrm{H} \quad$ NMR $\quad$ spectrum of $\quad$ 5,15-bis(4-cyanophenyl)-10,20-bis(2,4,6trimethylphenyl)porphyrin, 32 in $\mathrm{CDCl}_{3}$.

Figure S31 ESI-MS spectrum of 5,10,15,20-Tetrakis(4-nitrophenyl)porphyrin, 3 in $\mathrm{CH}_{3} \mathrm{CN}$ shows the measured spectrum with isotopic distribution pattern.

Figure S32 ESI-MS spectrum of 5,10,15,20-Tetrakis(4,7-dimethoxynaphthalen-1yl)porphyrin, 16 in $\mathrm{CH}_{3} \mathrm{CN}$ shows the measured spectrum with isotopic distribution pattern.

Figure S33 ESI-MS spectrum of 5,15-bis(4-cyanophenyl)-10,20-bis(4nitrophenyl)porphyrin, 24 in $\mathrm{CH}_{3} \mathrm{CN}$ shows the measured spectrum with isotopic distribution pattern. 


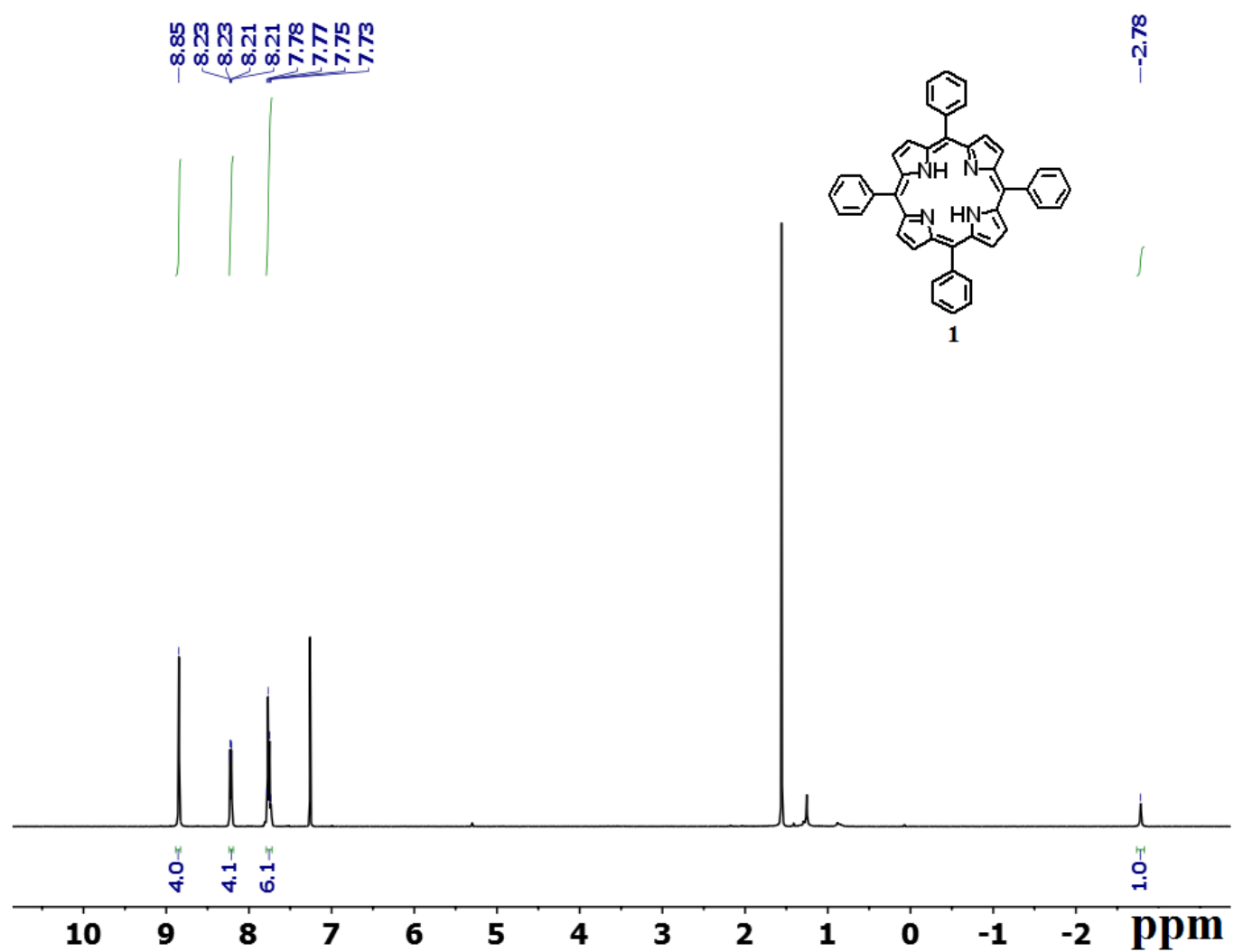

Figure S1 $\quad{ }^{1} \mathrm{H}$ NMR spectrum of 5,10,15,20-Tetraphenylporphyrin, $\mathbf{1}$ in $\mathrm{CDCl}_{3}$. 

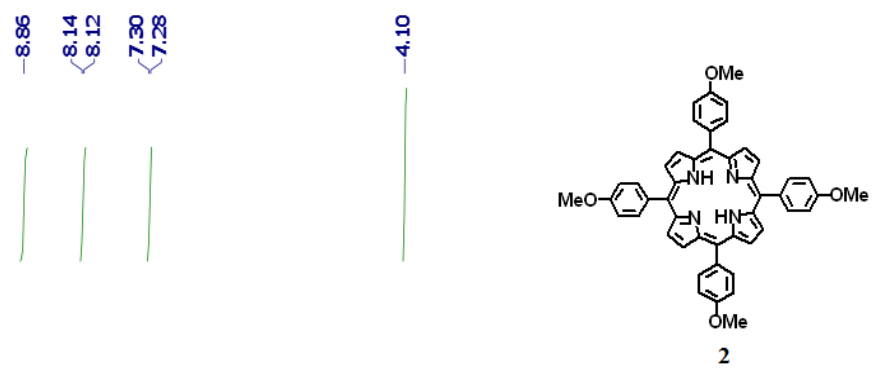

$\stackrel{n}{N}$

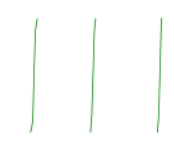

$$
\stackrel{9}{9}
$$

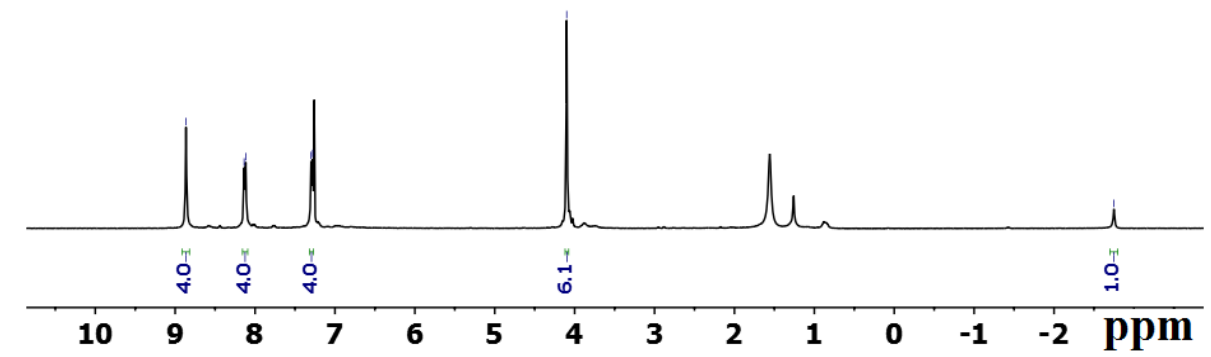

Figure S2 $\quad{ }^{1} \mathrm{H}$ NMR spectrum of 5,10,15,20-Tetrakis(4-methoxyphenyl)porphyrin, 2 in $\mathrm{CDCl}_{3}$. 


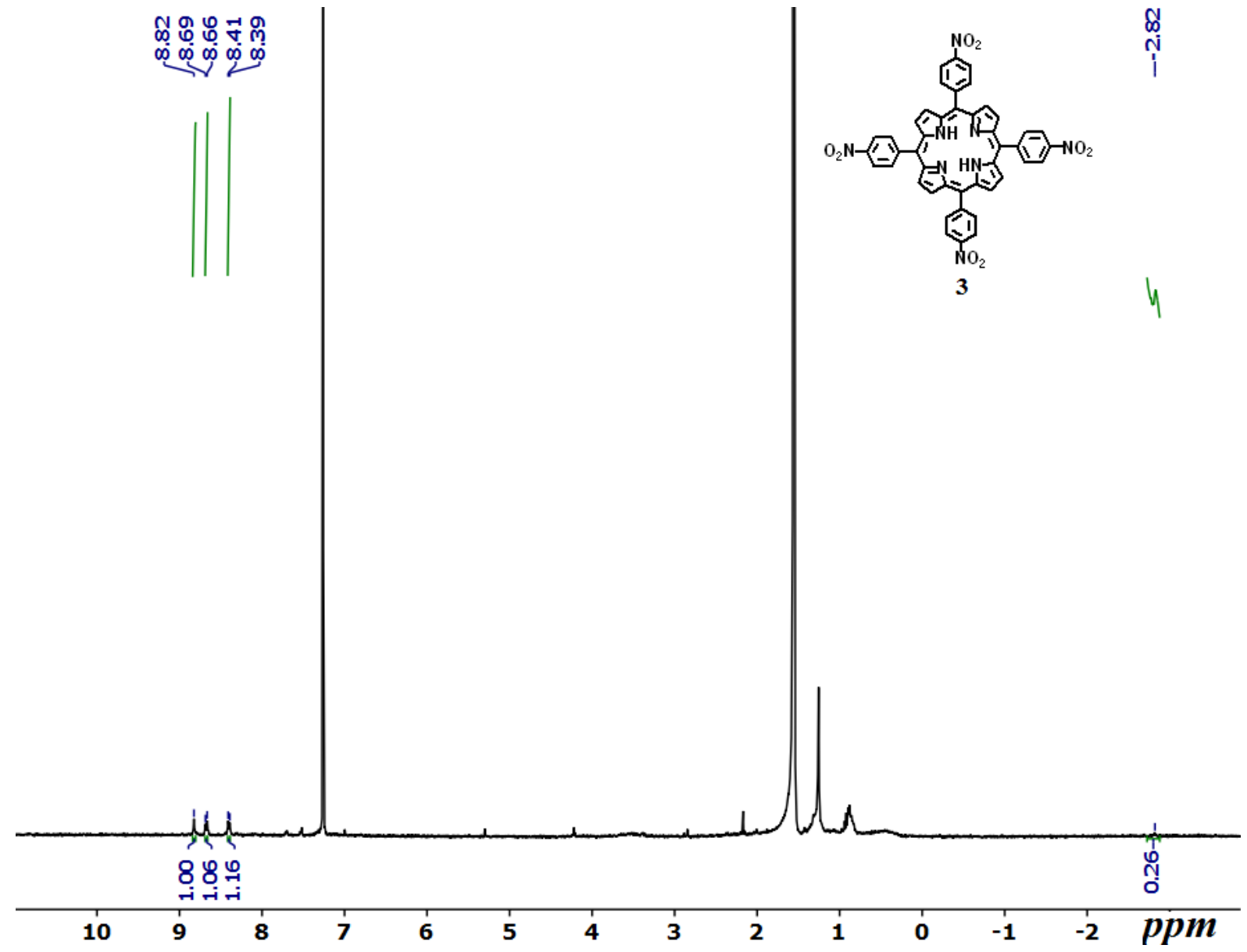

Figure S3 $\quad{ }^{1} \mathrm{H}$ NMR spectrum of 5,10,15,20-Tetrakis(4-nitrophenyl)porphyrin, $\mathbf{3}$ in $\mathrm{CDCl}_{3}$. 


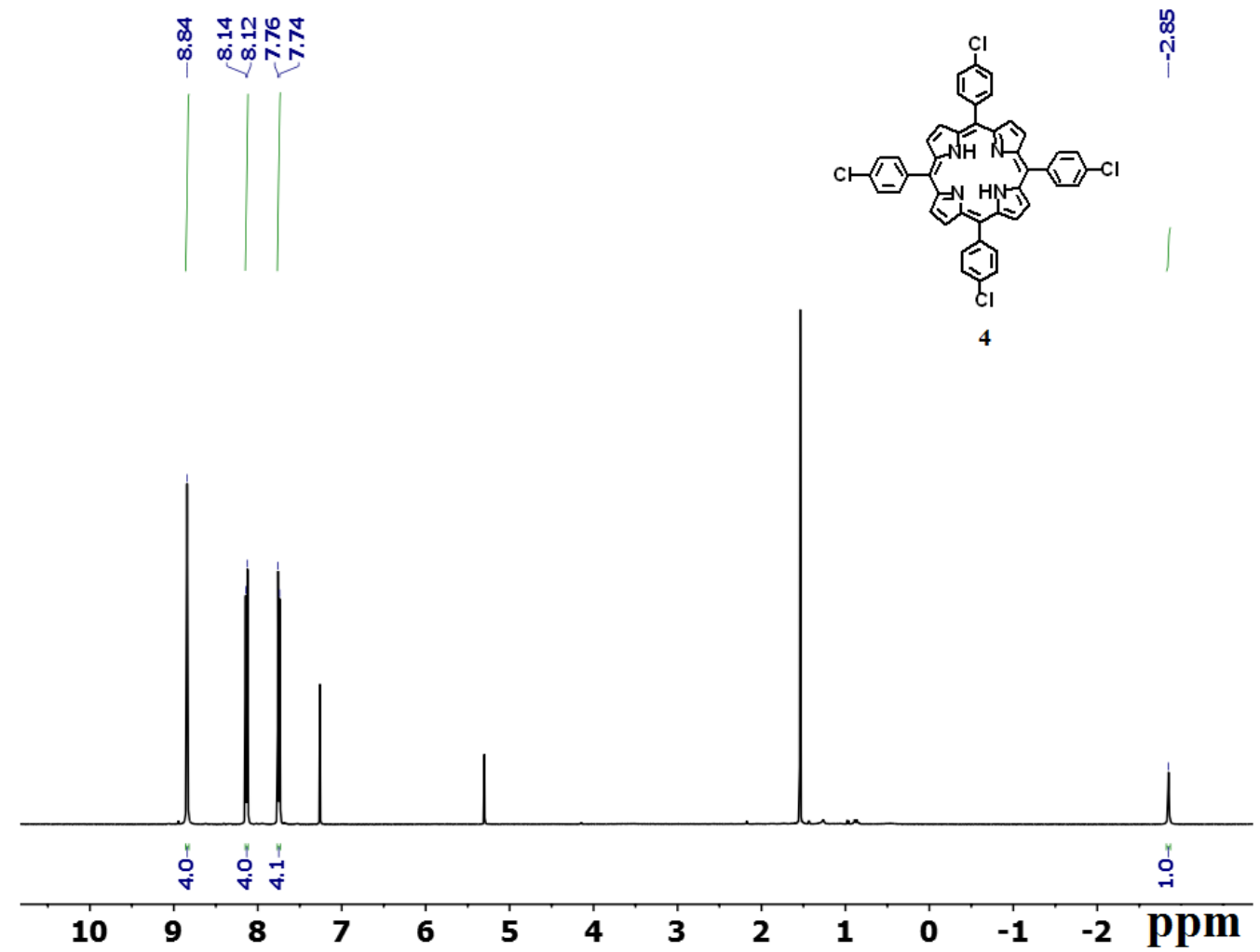

Figure S4 $\quad{ }^{1} \mathrm{H}$ NMR spectrum of 5,10,15,20-Tetrakis(4-chlorophenyl)porphyrin, 4 in $\mathrm{CDCl}_{3}$. 


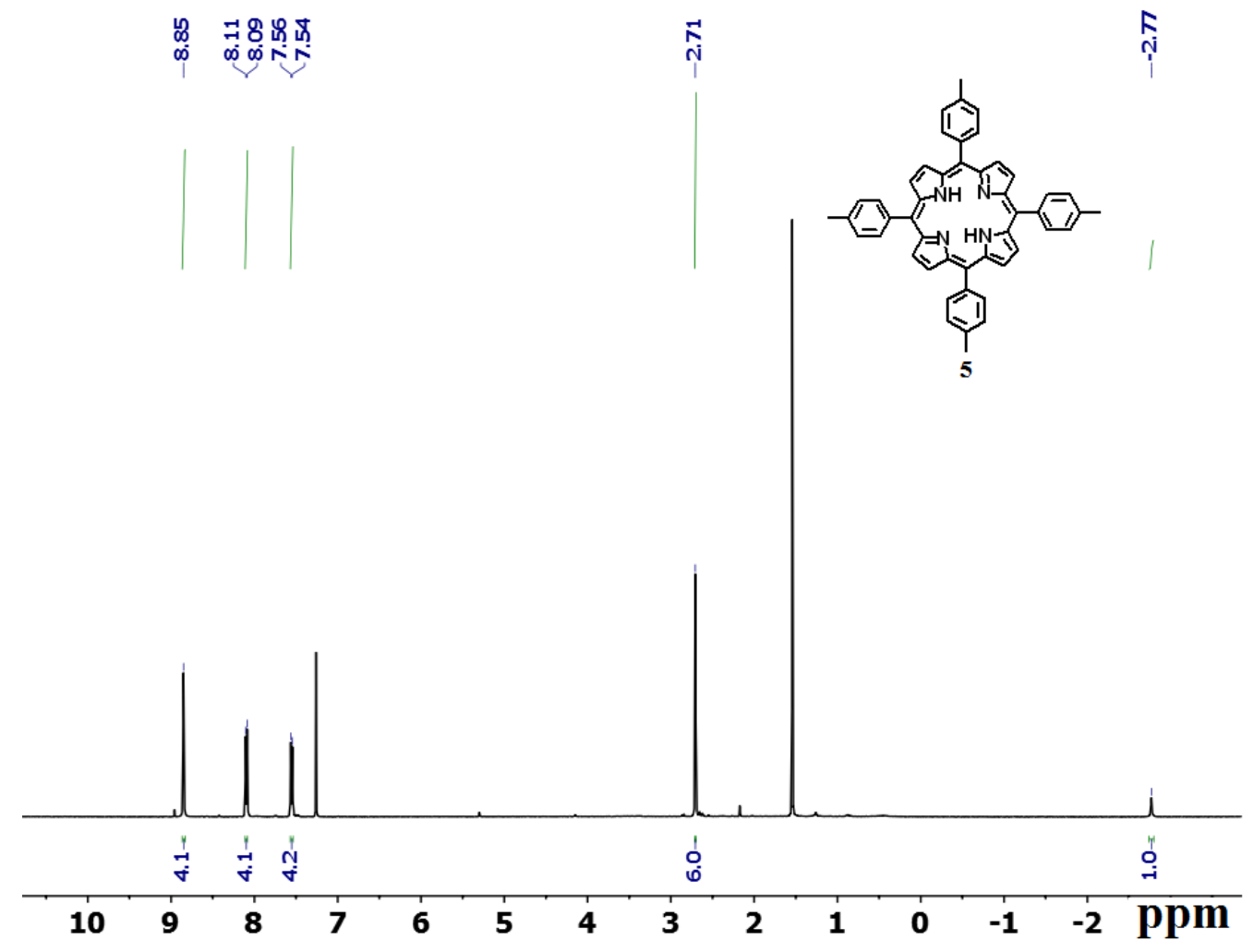

Figure S5 $\quad{ }^{1} \mathrm{H}$ NMR spectrum of 5,10,15,20-Tetrakis(4-methylphenyl)porphyrin, 5 in $\mathrm{CDCl}_{3}$. 

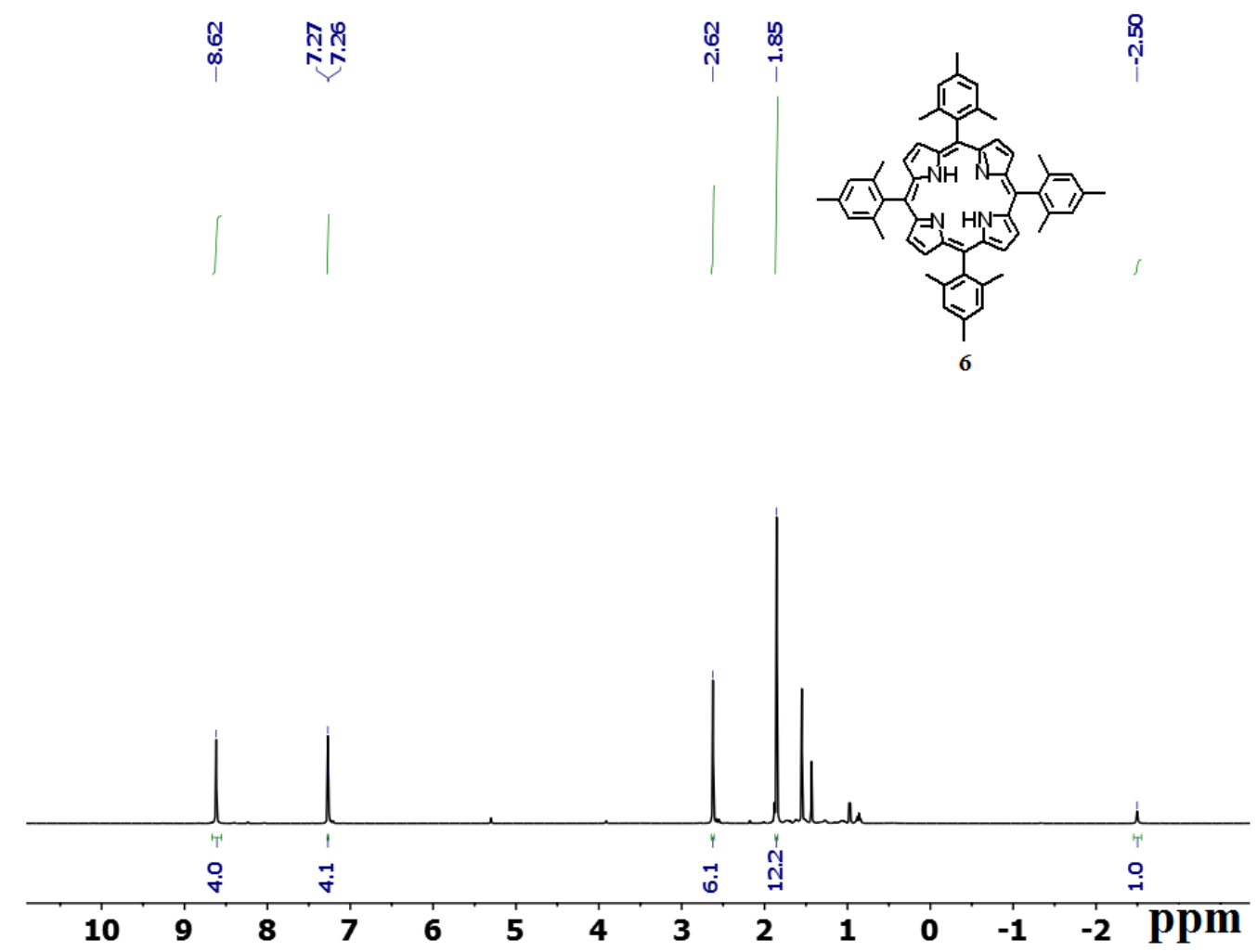

Figure S6 $\quad{ }^{1} \mathrm{H}$ NMR spectrum of 5,10,15,20-Tetrakis(2,4,6-trimethylphenyl)porphyrin, 6 in $\mathrm{CDCl}_{3}$. 


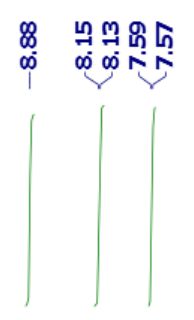

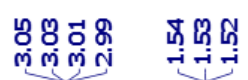
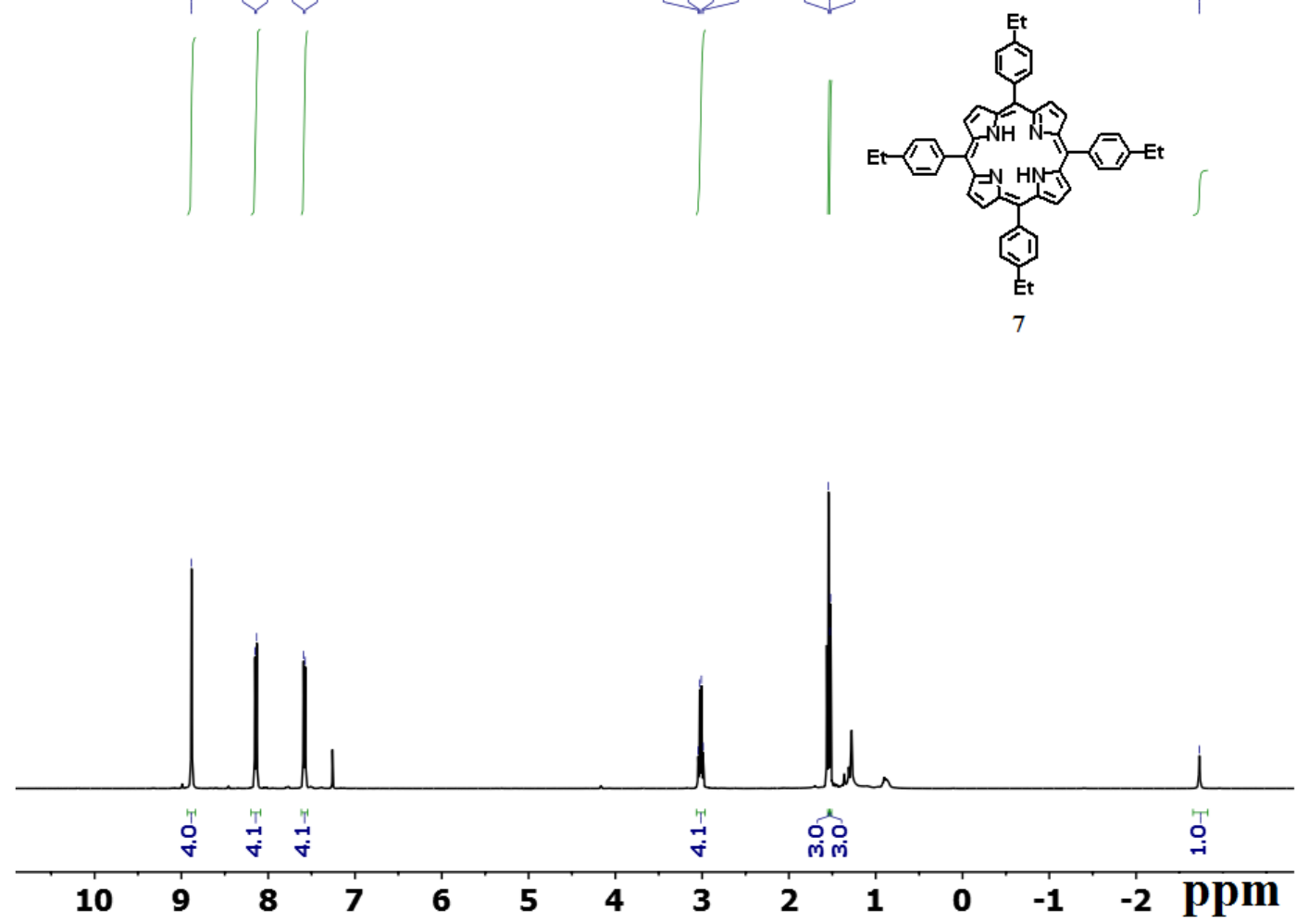

Figure S7 $\quad{ }^{1} \mathrm{H} \quad$ NMR spectrum of 5,10,15,20-Tetrakis-(4-ethylphenyl)porphyrin, 7 in $\mathrm{CDCl}_{3}$. 


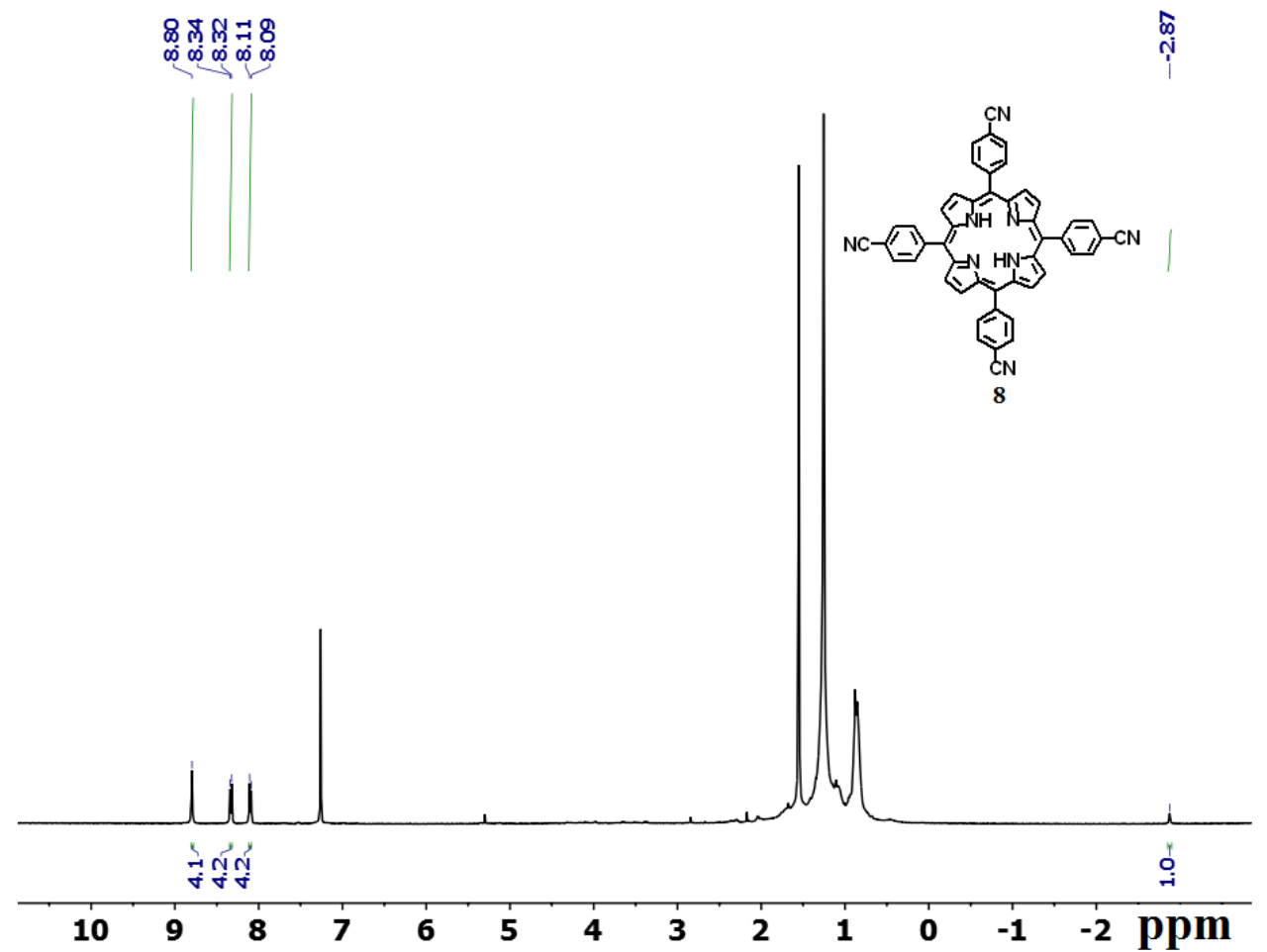

Figure S8 $\quad{ }^{1} \mathrm{H}$ NMR spectrum of 5,10,15,20-Tetrakis(4-cyanophenyl)porphyrin, 8 in $\mathrm{CDCl}_{3}$. 


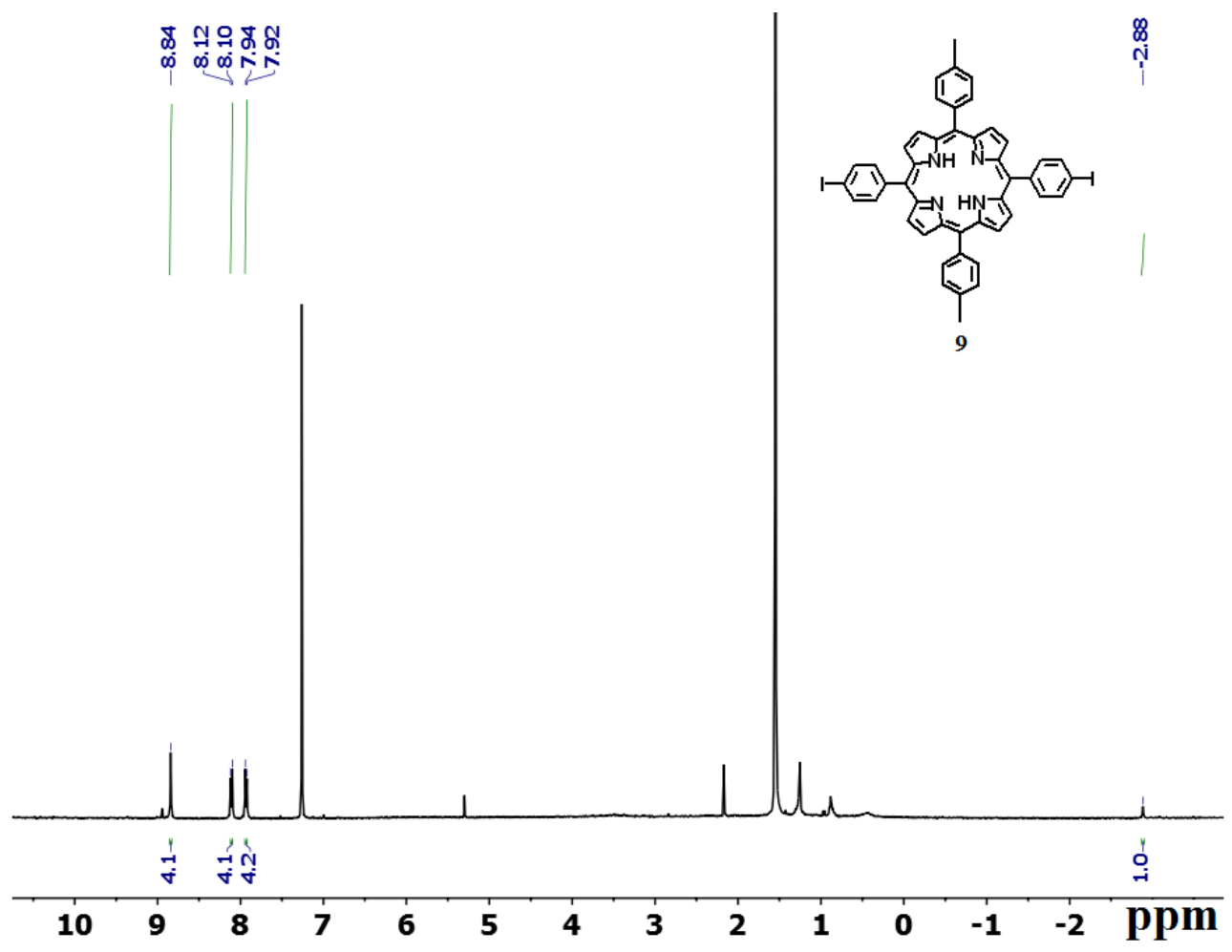

Figure S9 $\quad{ }^{1} \mathrm{H}$ NMR spectrum of 5,10,15,20-Tetrakis(4-iodophenyl)porphyrin, 9 in $\mathrm{CDCl}_{3}$. 

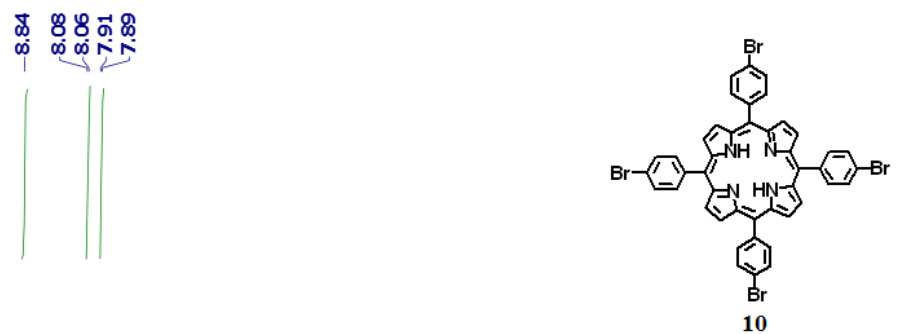

$$
\stackrel{\aleph}{i}
$$

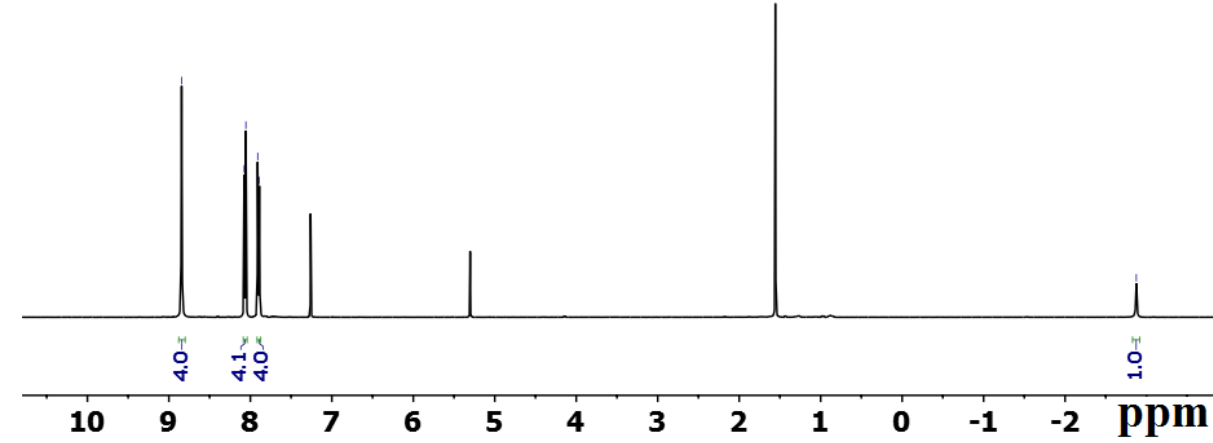

Figure S10 $\quad{ }^{1} \mathrm{H}$ NMR spectrum of 5,10,15,20-Tetrakis(4-bromophenyl)porphyrin, 10 in $\mathrm{CDCl}_{3}$. 


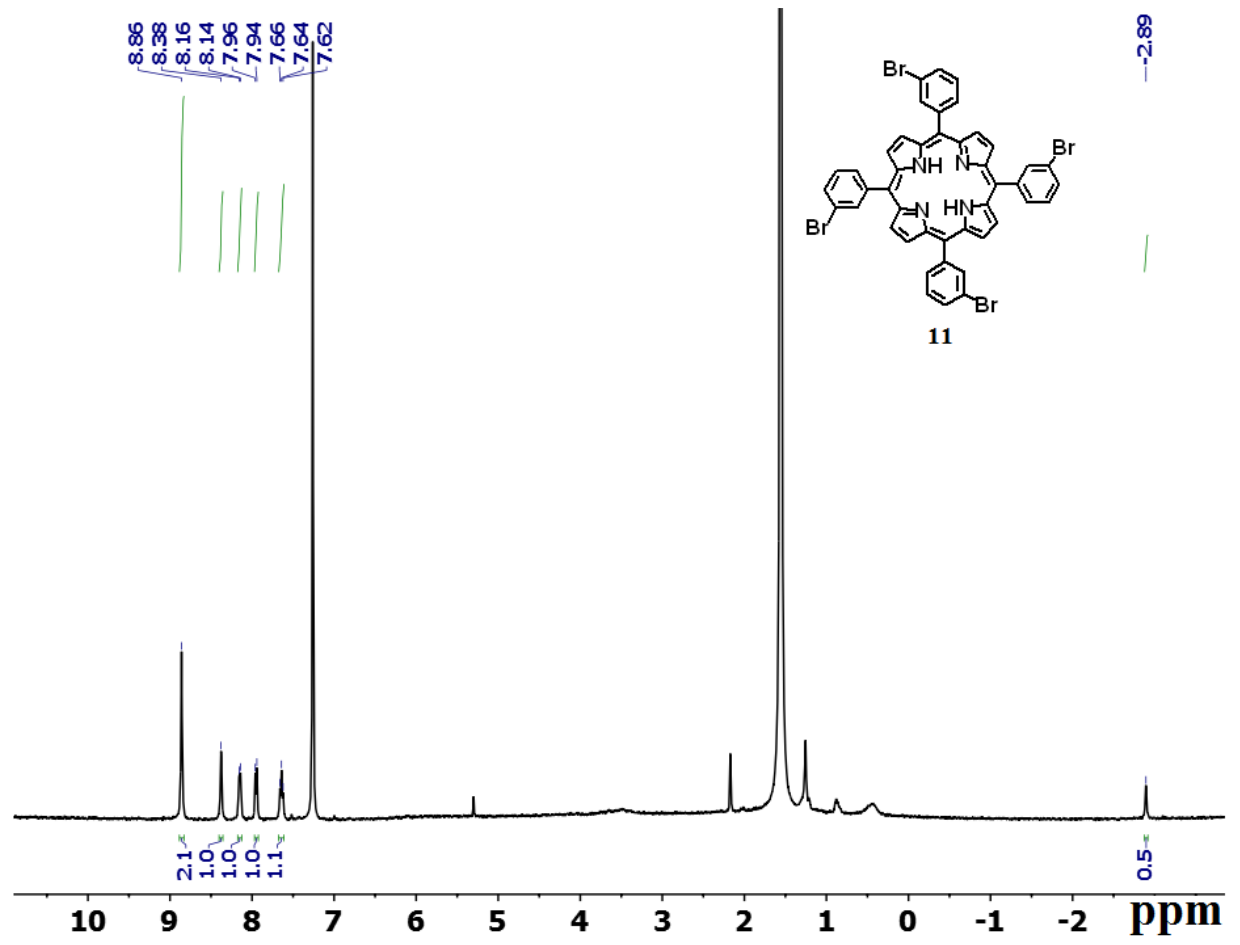

Figure S11 ${ }^{1} \mathrm{H}$ NMR spectrum of 5,10,15,20-Tetrakis(3-bromophenyl)porphyrin, 11 in $\mathrm{CDCl}_{3}$. 


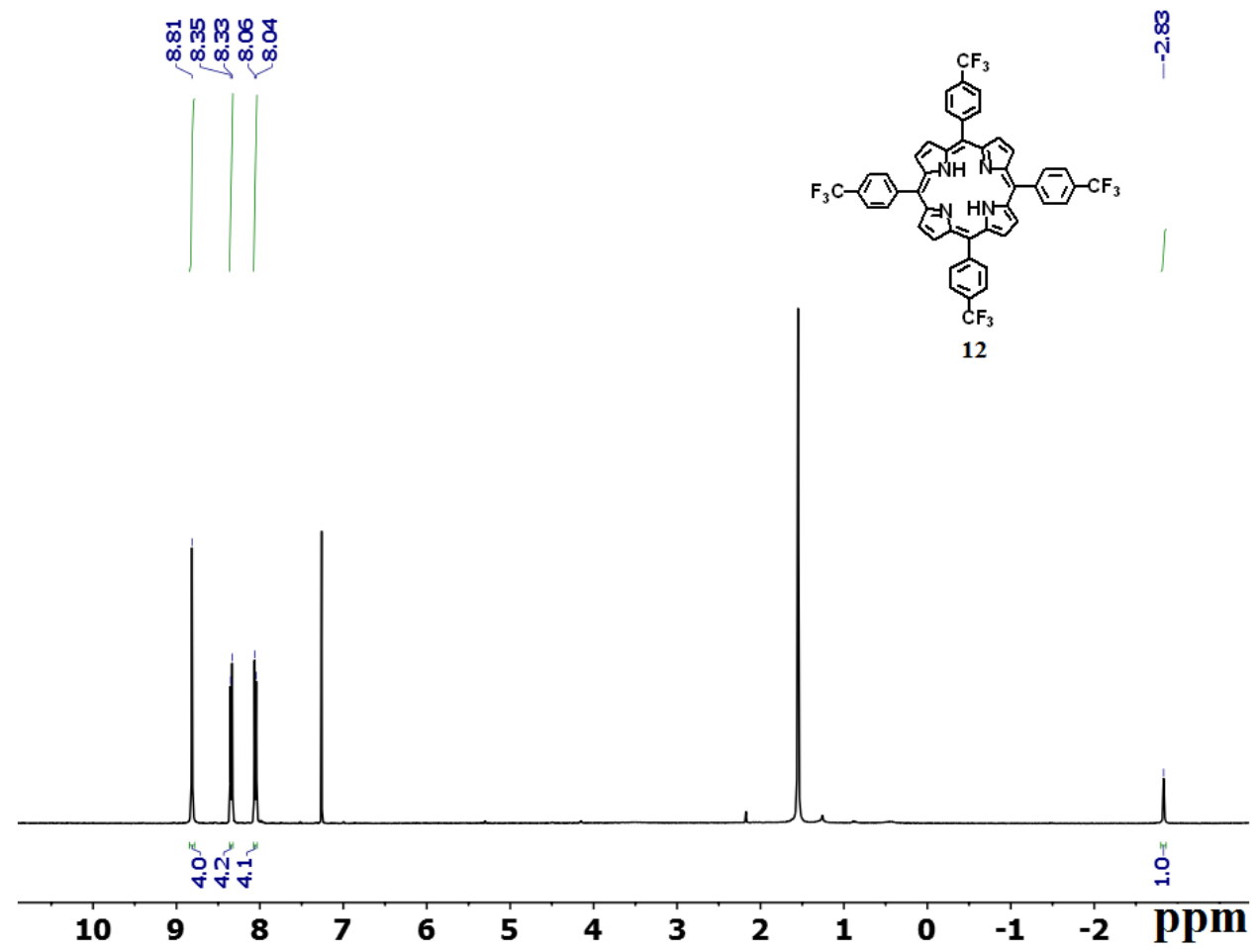

Figure S12 $\quad{ }^{1} \mathrm{H}$ NMR spectrum of 5,10,15,20-(tetra-4-trifluoromethylphenyl)porphyrin, 12 in $\mathrm{CDCl}_{3}$. 


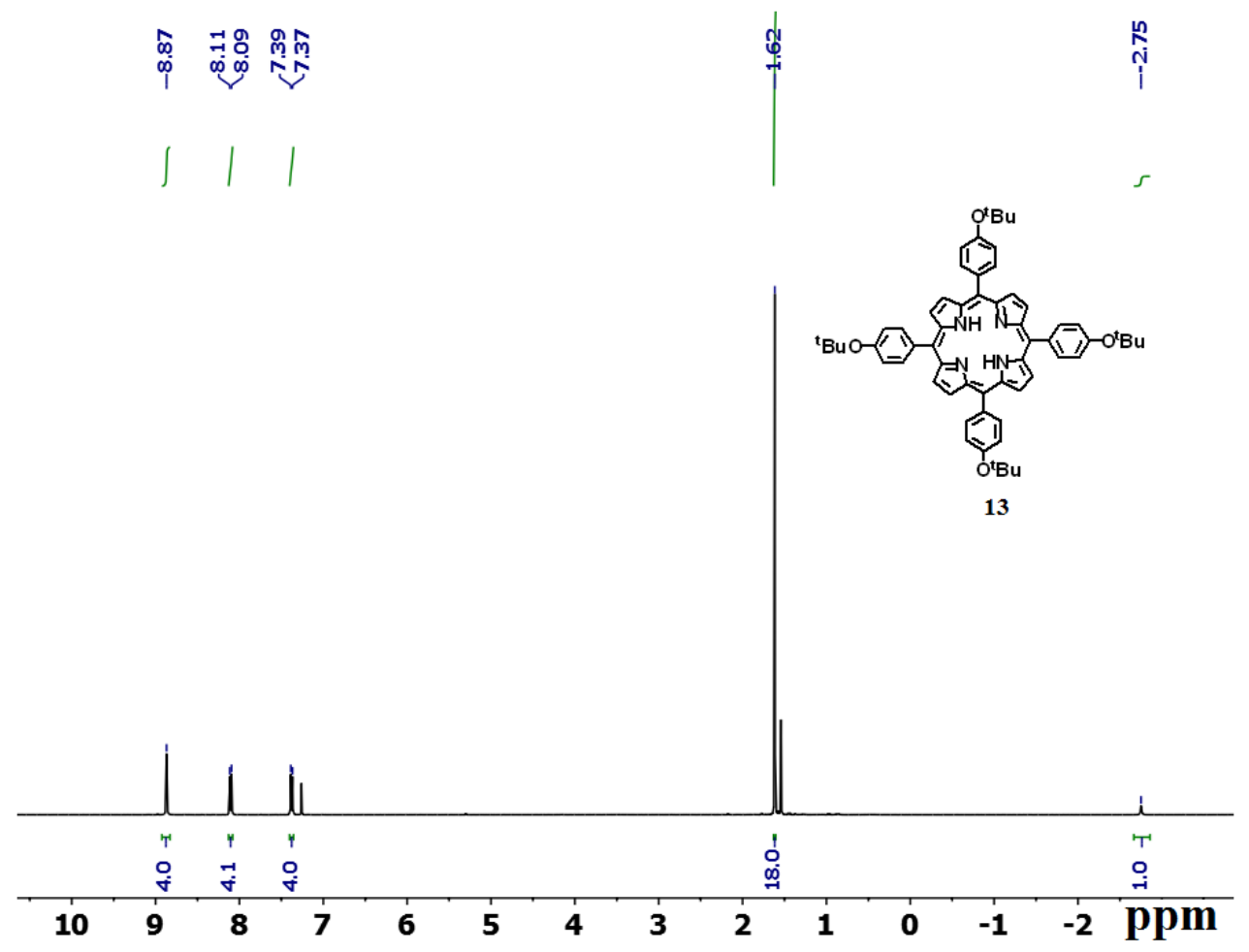

Figure S13 ${ }^{1} \mathrm{H}$ NMR spectrum of 5,10,15,20-Tetrakis(4-butoxyphenyl)porphyrin, 13 in $\mathrm{CDCl}_{3}$. 


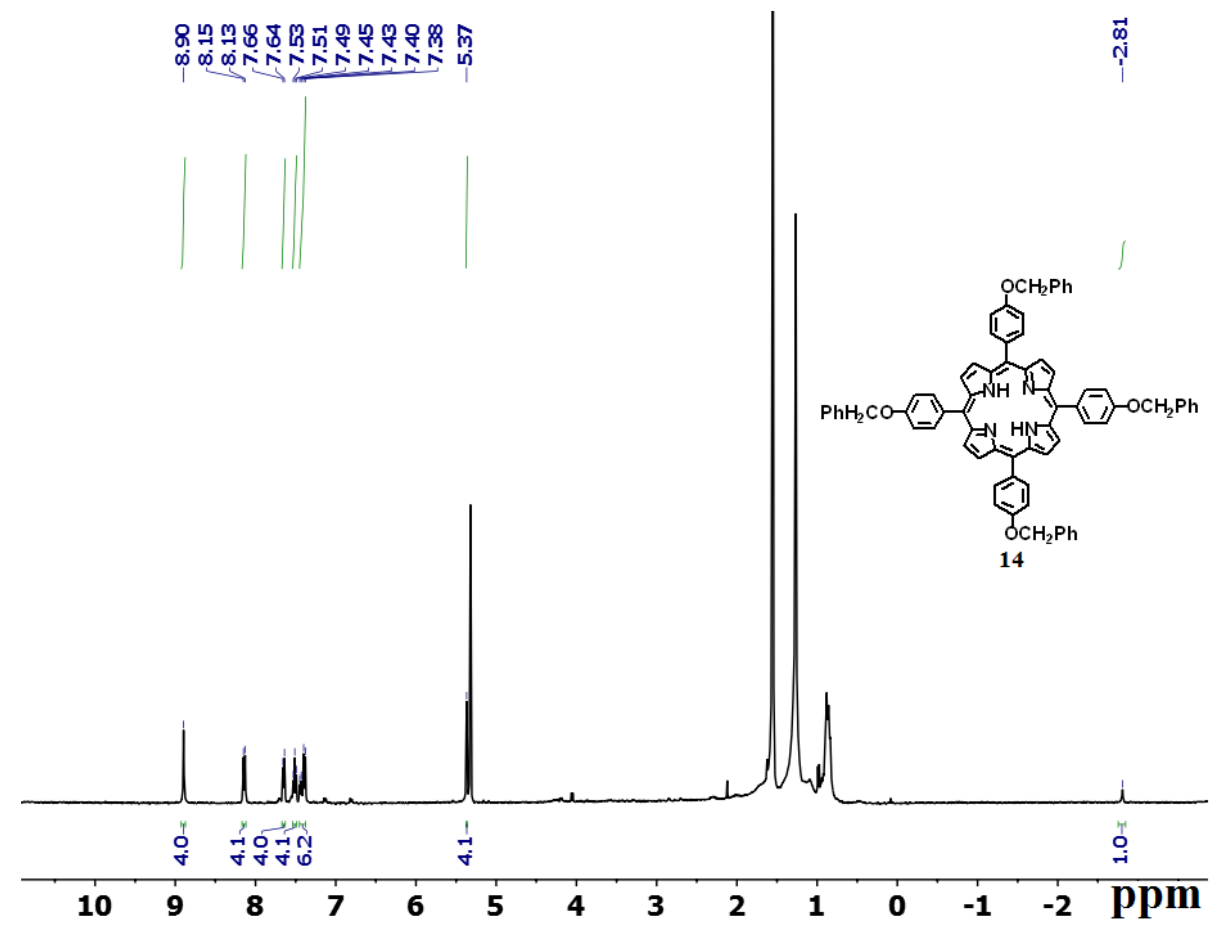

Figure S14 ${ }^{1} \mathrm{H}$ NMR spectrum of 5,10,15,20-Tetrakis[4-(benzyloxy)phenyl]porphyrin, 14 in $\mathrm{CD}_{2} \mathrm{Cl}_{2}$. 


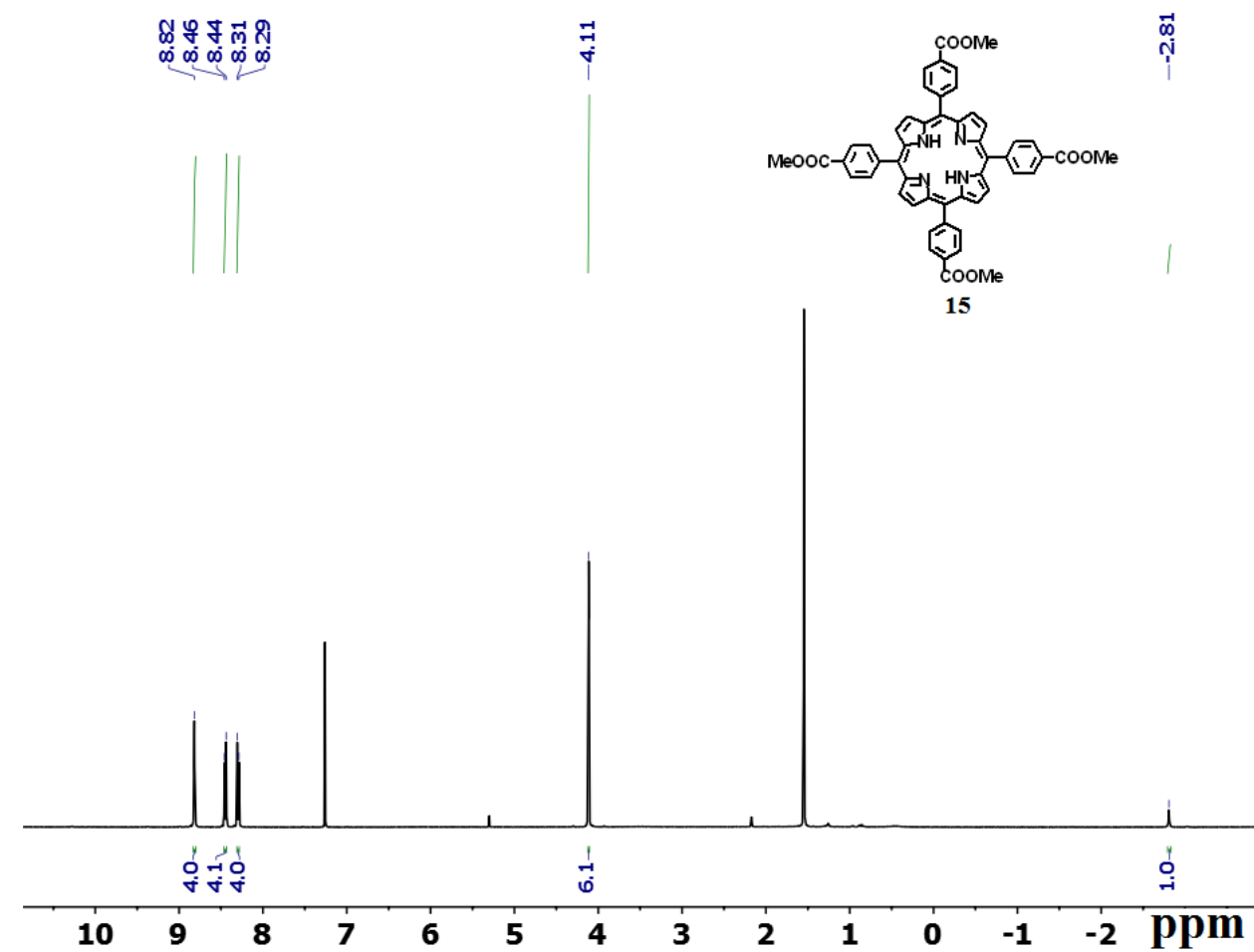

Figure S15 $\quad{ }^{1} \mathrm{H} \quad$ NMR $\quad$ spectrum $\quad$ of $\quad 5,10,15,20$-Tetrakis(4methoxycarbonylphenyl)porphyrin, 15 in $\mathrm{CDCl}_{3}$. 


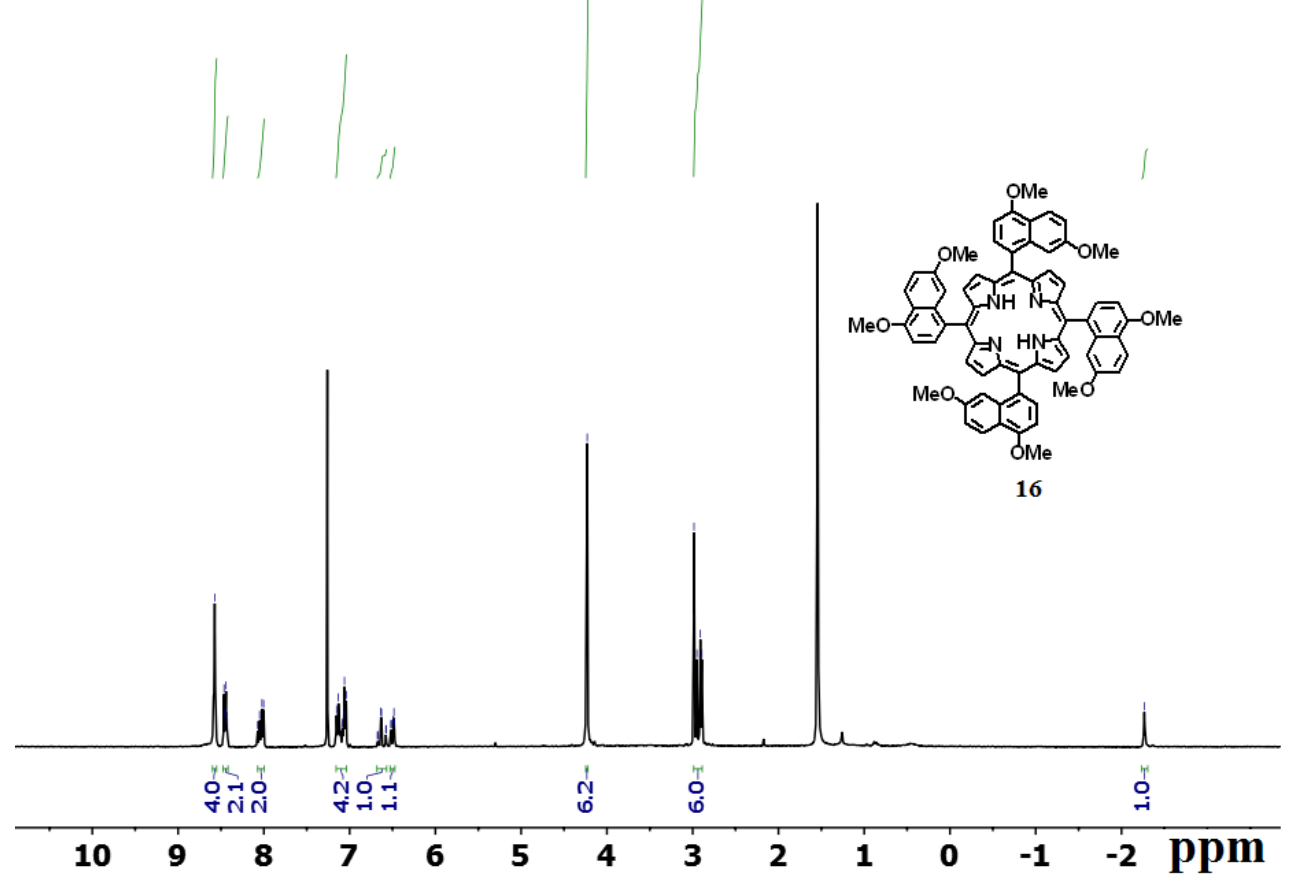

Figure S16 $\quad{ }^{1} \mathrm{H} \quad$ NMR spectrum of 5,10,15,20-Tetrakis(4,7-dimethoxynaphthalen-1yl)porphyrin, 16 in $\mathrm{CDCl}_{3}$. 


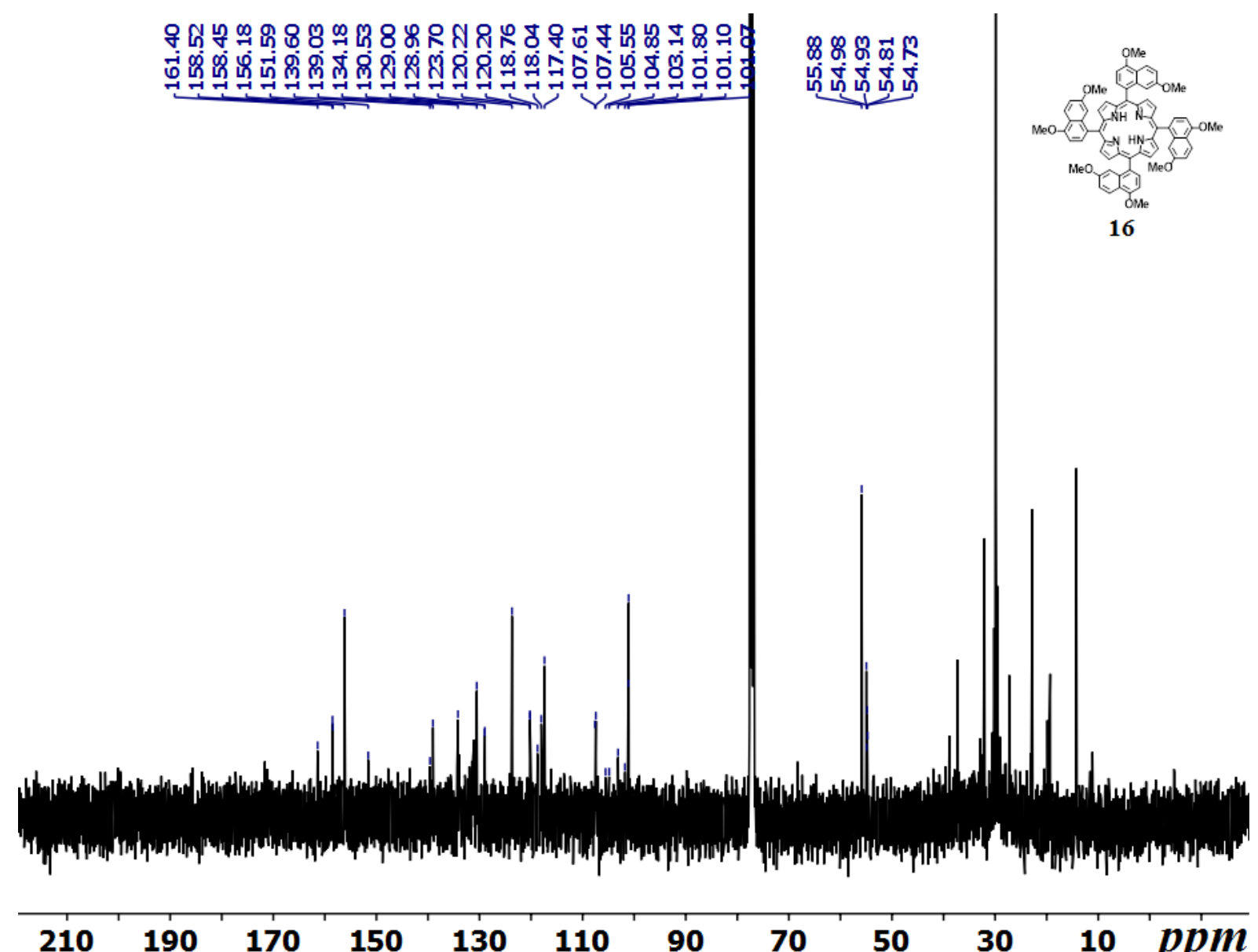

Figure S17 $\quad{ }^{13} \mathrm{C}\left\{{ }^{1} \mathrm{H}\right\}$ NMR $\quad(101 \quad \mathrm{MHz}) \quad$ spectrum of $5,10,15,20-$ Tetrakis(4,7-dimethoxynaphthalen-1-yl)porphyrin, 16 in $\mathrm{CDCl}_{3}$. 


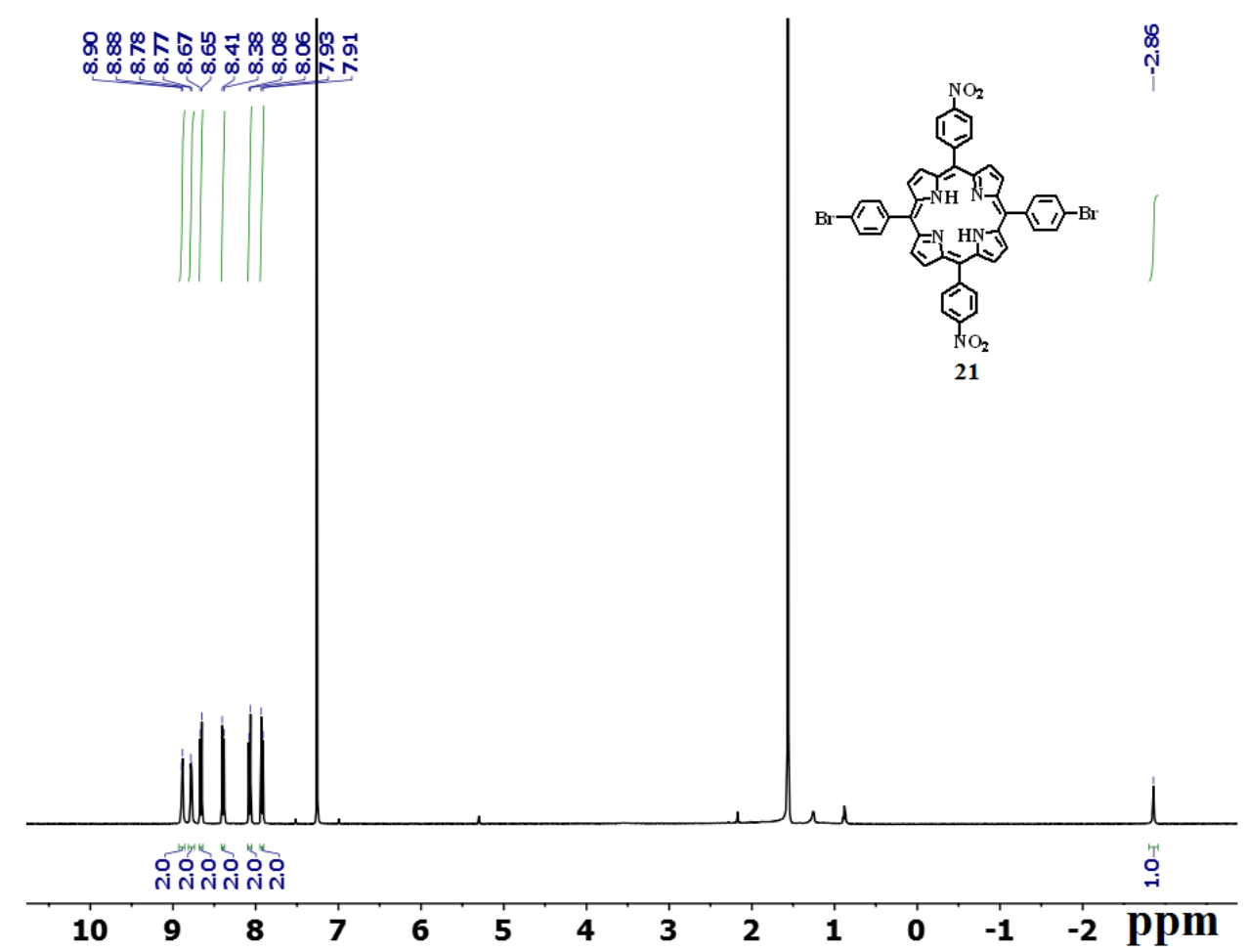

Figure S18 $\quad{ }^{1} \mathrm{H} \quad$ NMR $\quad$ spectrum of $\quad$ 5,15-Bis(4-bromophenyl)-10,20-bis(4nitrophenyl)porphyrin, 21 in $\mathrm{CDCl}_{3}$. 


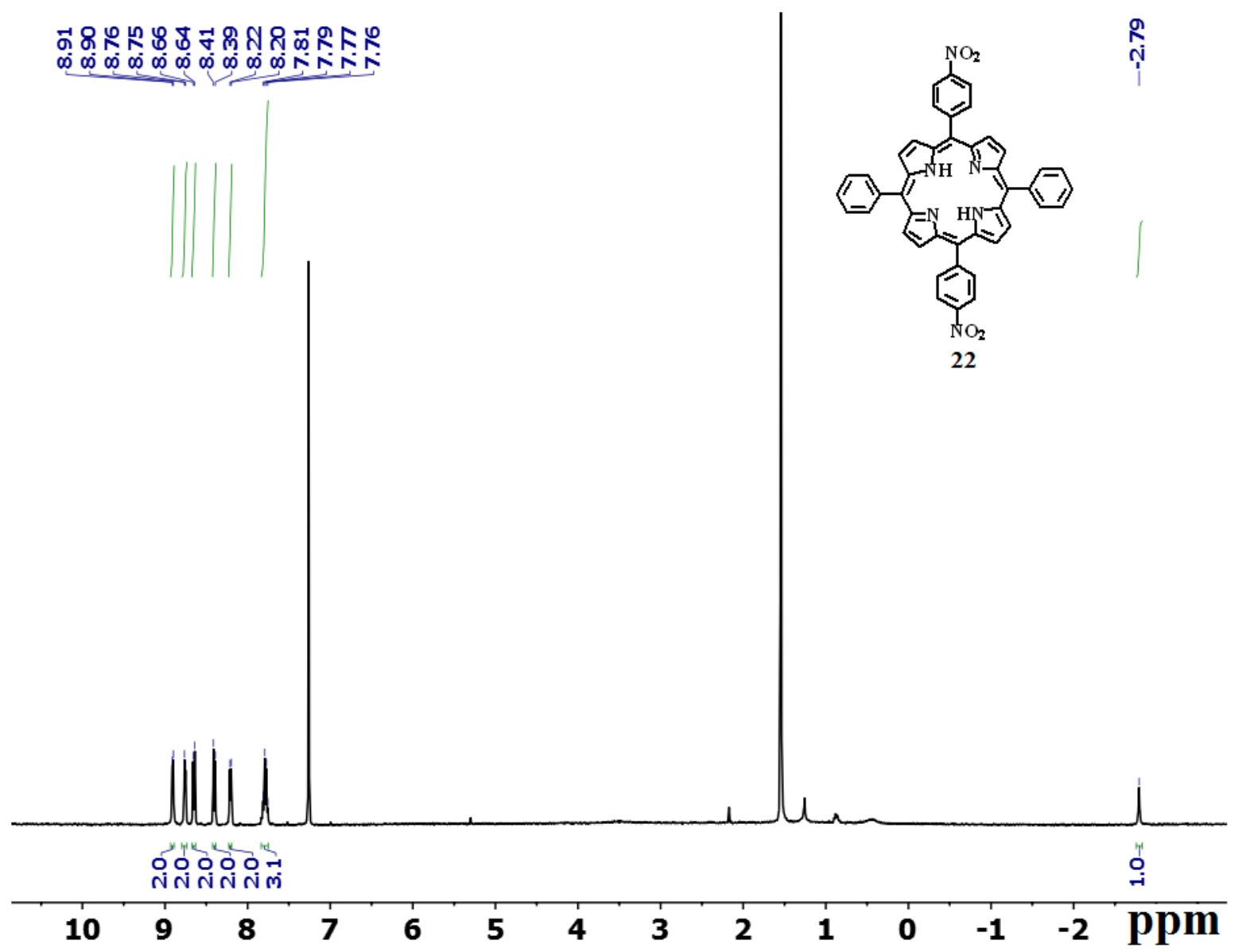

Figure S19 ${ }^{1} \mathrm{H}$ NMR spectrum of 5,15-Bis(4-nitrophenyl)-10,20-diphenylporphyrin, 22 in $\mathrm{CDCl}_{3}$. 


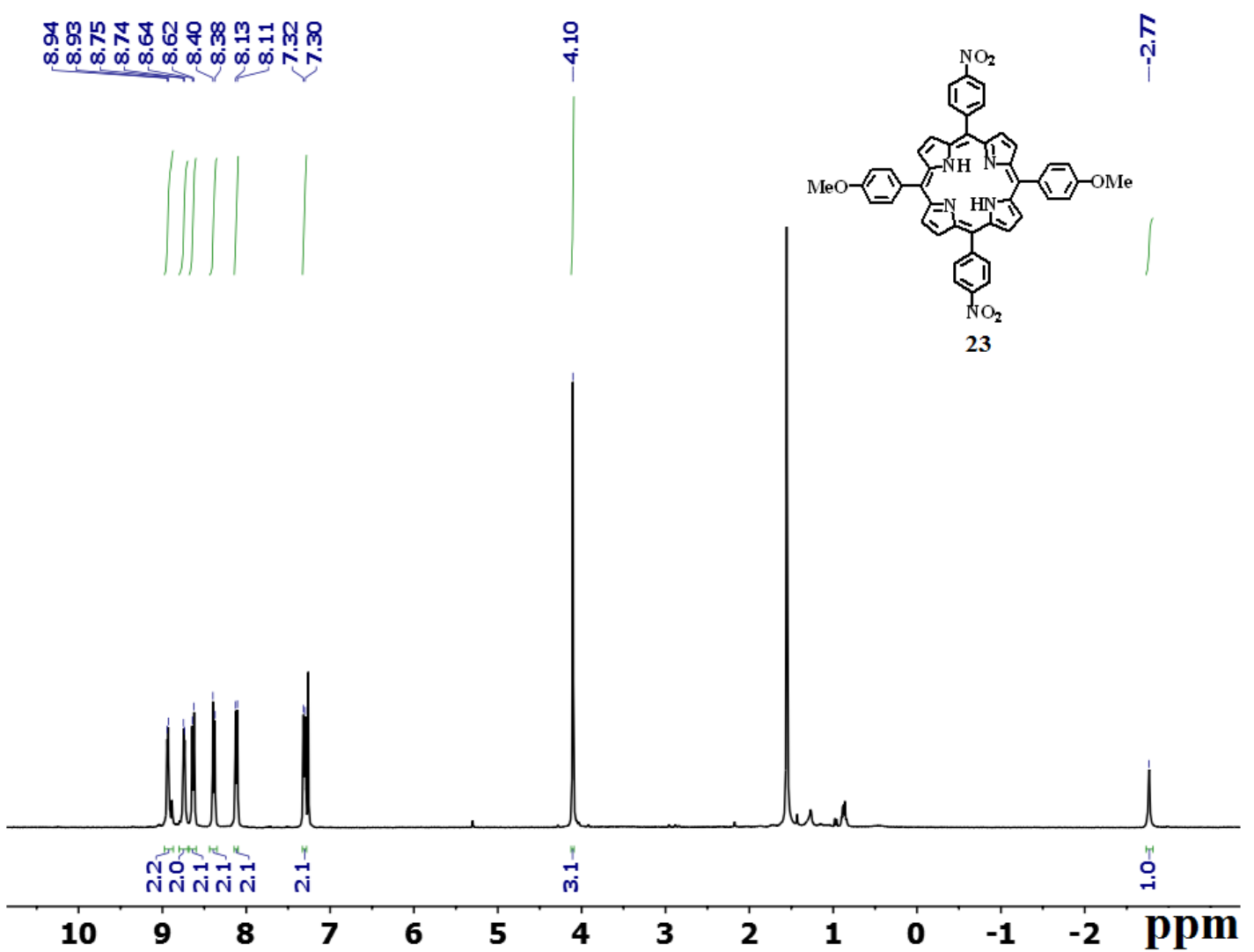

Figure S20 $\quad{ }^{1} \mathrm{H} \quad$ NMR $\quad$ spectrum of $\quad$ 5,15-Bis(4-methoxyphenyl)-10,20-bis(4nitrophenyl)porphyrin, 23 in $\mathrm{CDCl}_{3}$. 


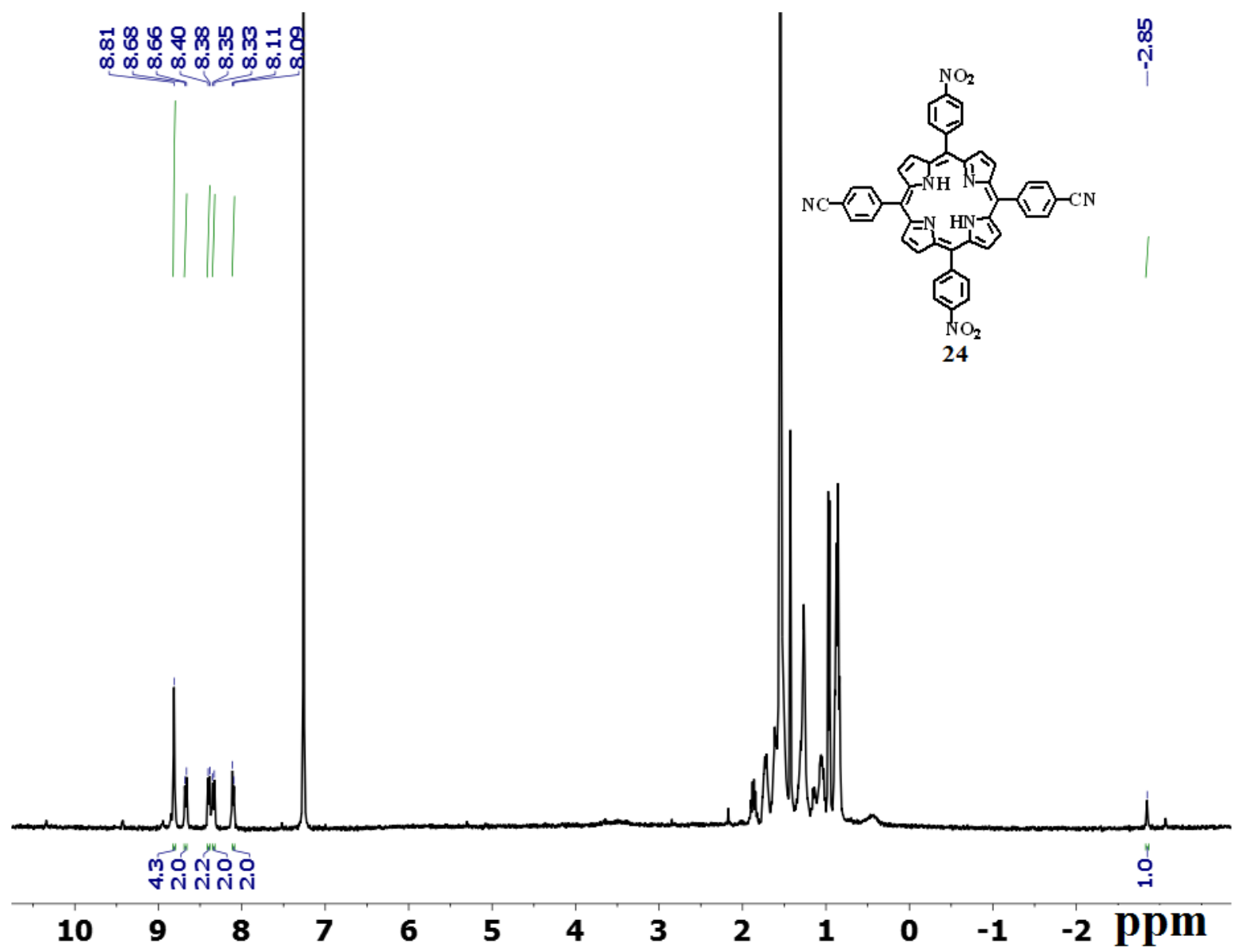

Figure S21 $\quad{ }^{1} \mathrm{H} \quad$ NMR $\quad$ spectrum of $\quad$ 5,15-bis(4-cyanophenyl)-10,20-bis(4nitrophenyl)porphyrin, 24 in $\mathrm{CDCl}_{3}$. 


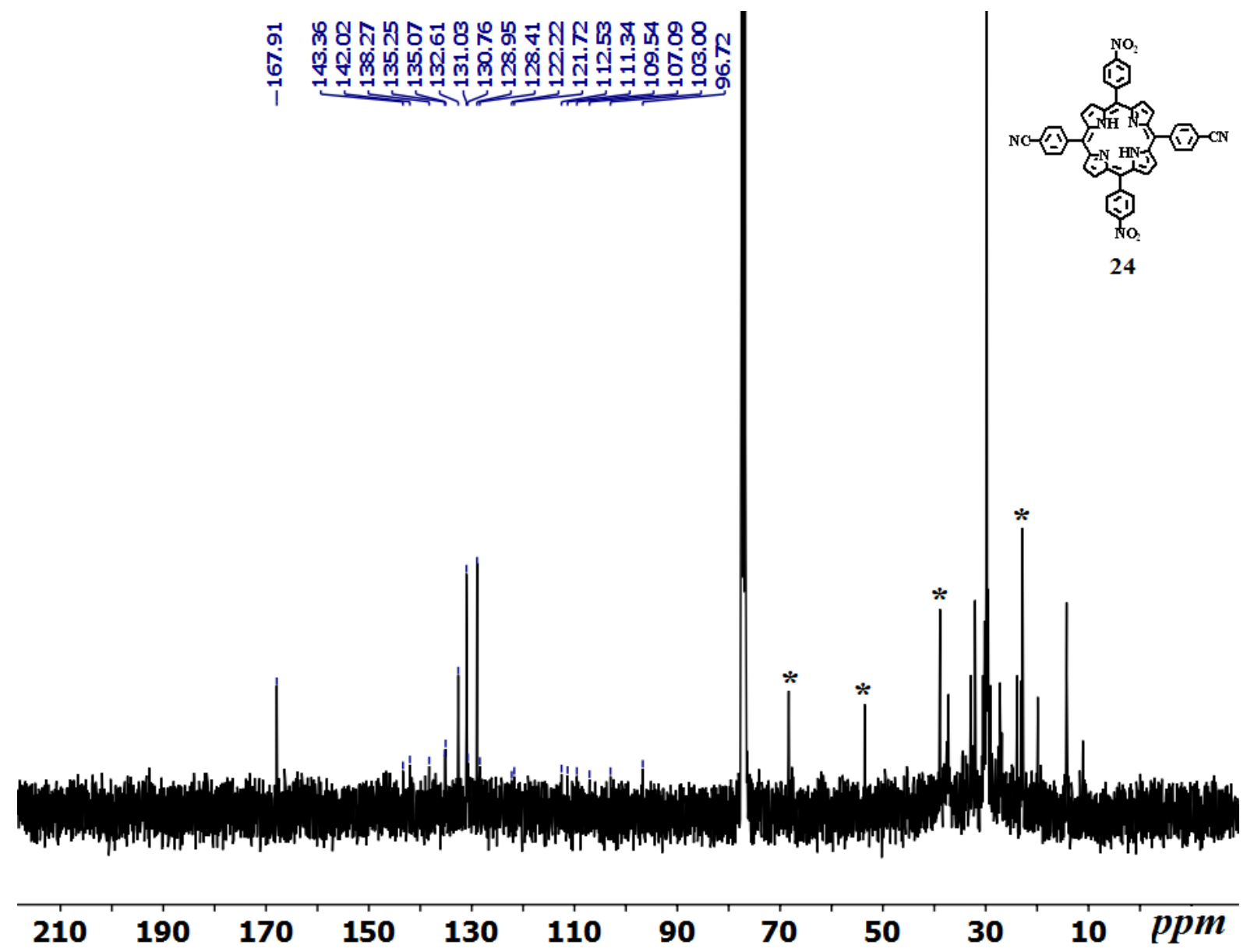

Figure S22 ${ }^{13} \mathrm{C}\left\{{ }^{1} \mathrm{H}\right\}$ NMR (101 MHz) spectrum of 5,15-bis(4-cyanophenyl)-10,20-bis(4nitrophenyl)porphyrin, 24 in $\mathrm{CDCl}_{3}$. 


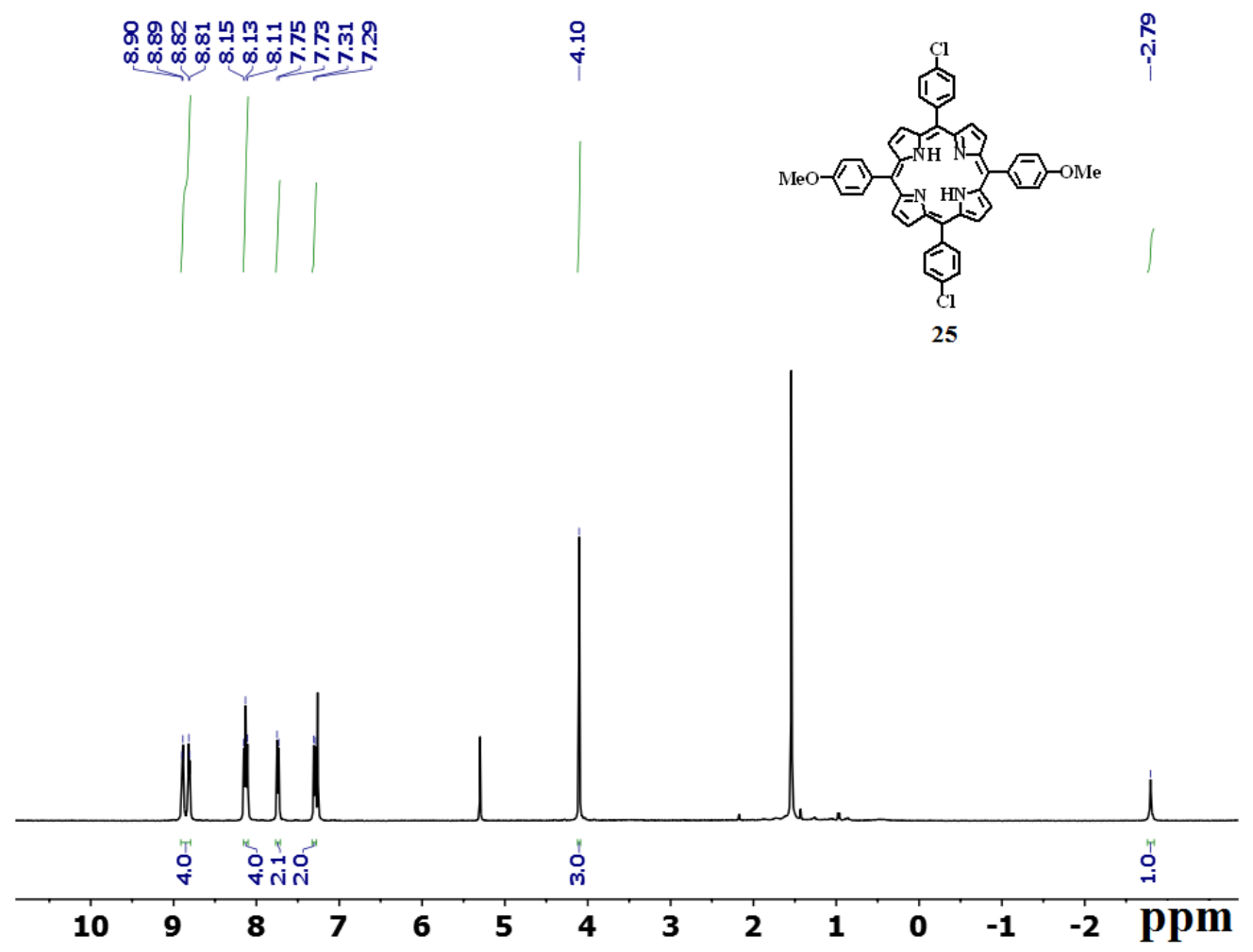

Figure S23 $\quad{ }^{1} \mathrm{H} \quad$ NMR $\quad$ spectrum of $\quad$ 5,15-Bis(4-methoxyphenyl)-10,20-(4chlorophenyl)porphyrin, 25 in $\mathrm{CDCl}_{3}$. 


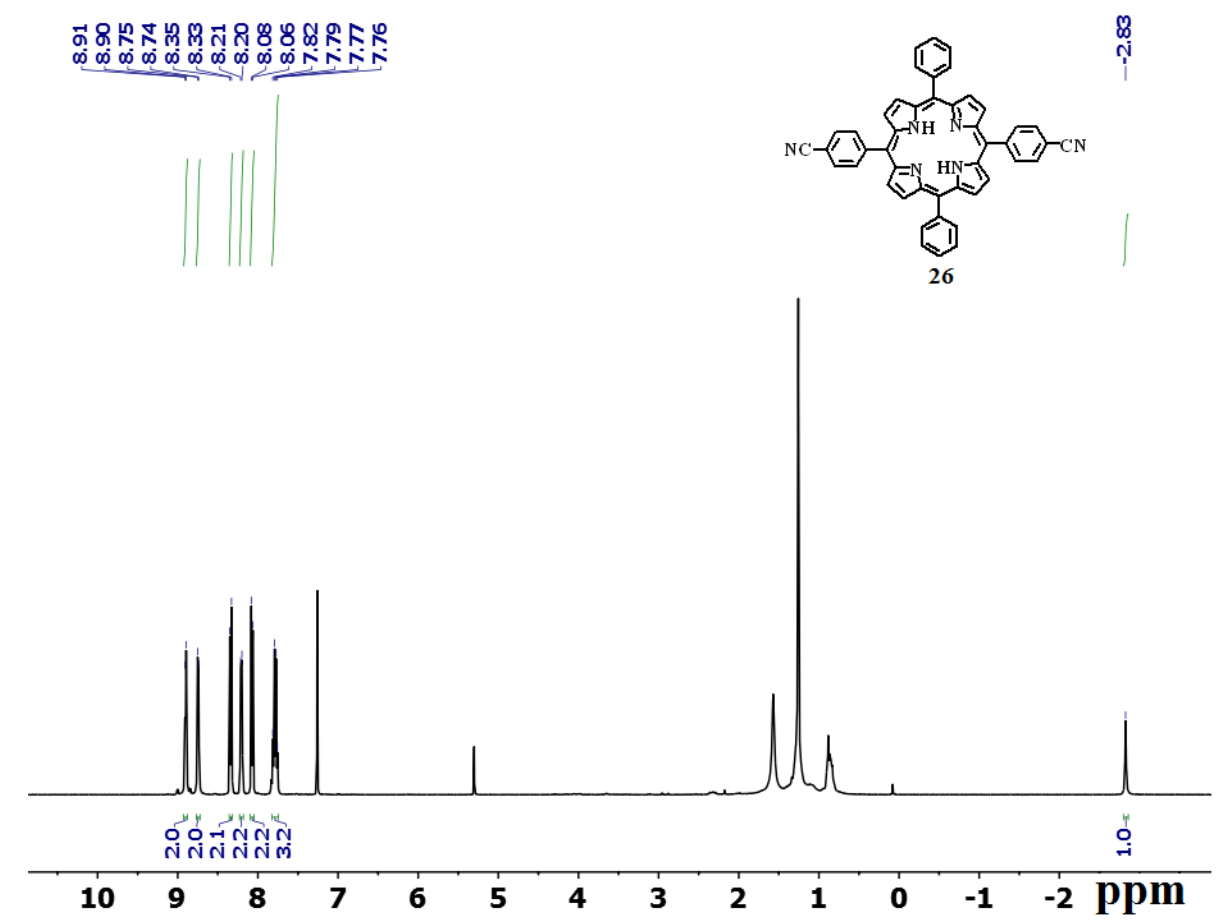

Figure S24 ${ }^{1} \mathrm{H}$ NMR spectrum of 5,15-Bis(4-cyanophenyl)-10,20-diphenylporphyrin, 26 in $\mathrm{CDCl}_{3}$. 


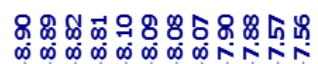

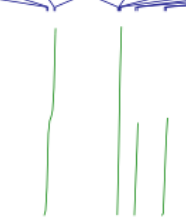

i

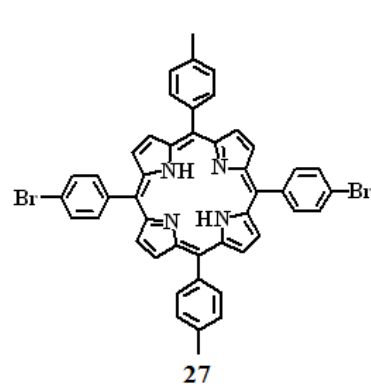

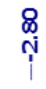

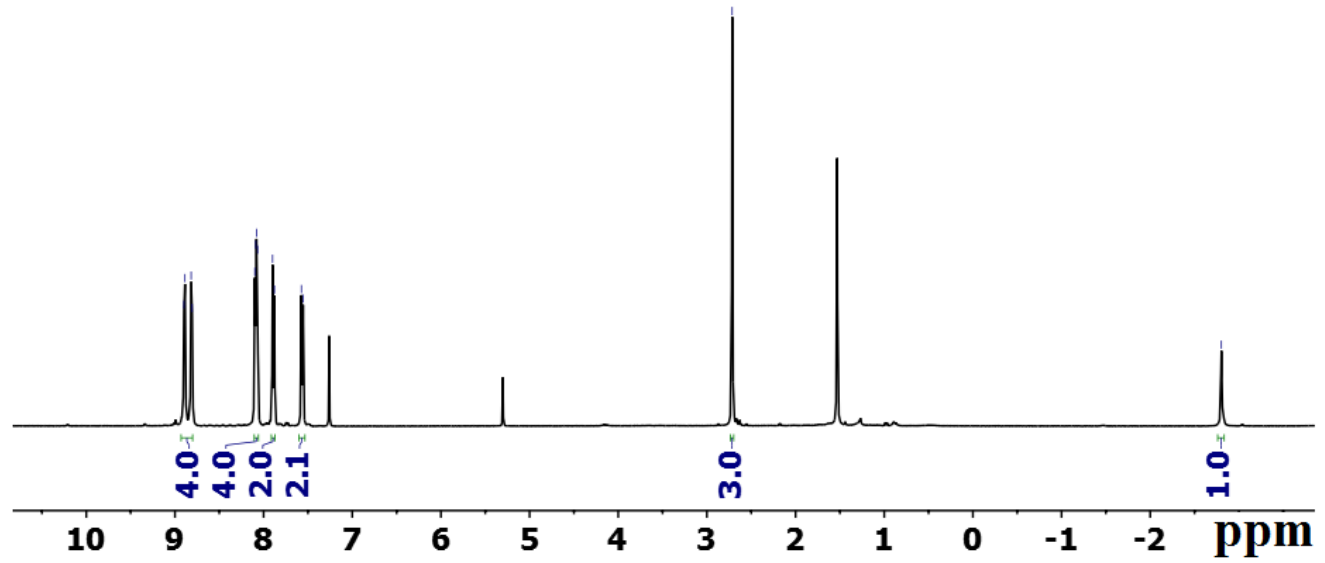

Figure S25 $\quad{ }^{1} \mathrm{H} \quad$ NMR $\quad$ spectrum of $\quad$ 5,15-Bis(4-bromophenyl)-10,20-(4methylphenyl)porphyrin, 27 in $\mathrm{CDCl}_{3}$. 


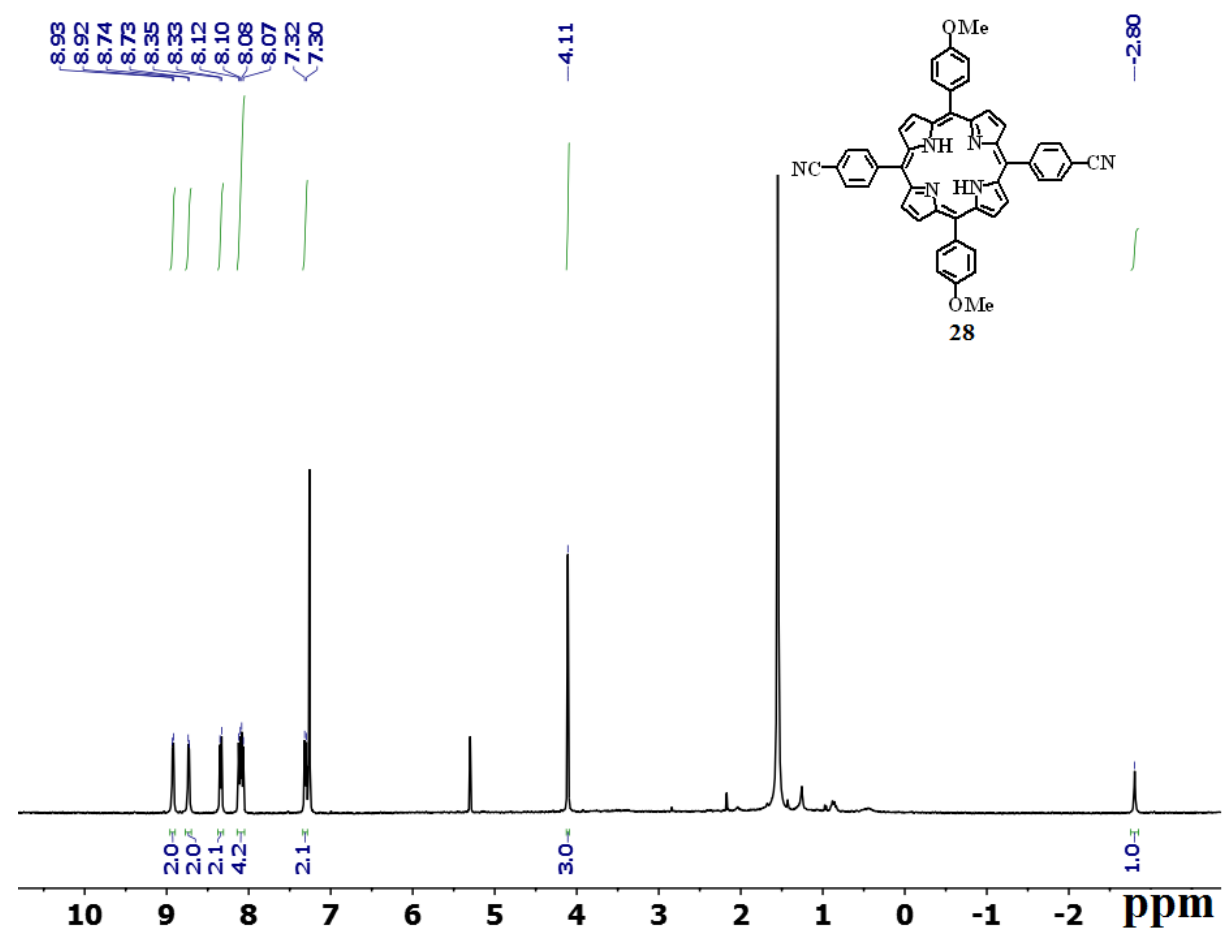

Figure S26 $\quad{ }^{1} \mathrm{H} \quad$ NMR $\quad$ spectrum $\quad$ of $\quad$ 5,15-bis(4-cyanophenyl)-10,20-bis(4methoxyphenyl)porphyrin, 28 in $\mathrm{CDCl}_{3}$. 


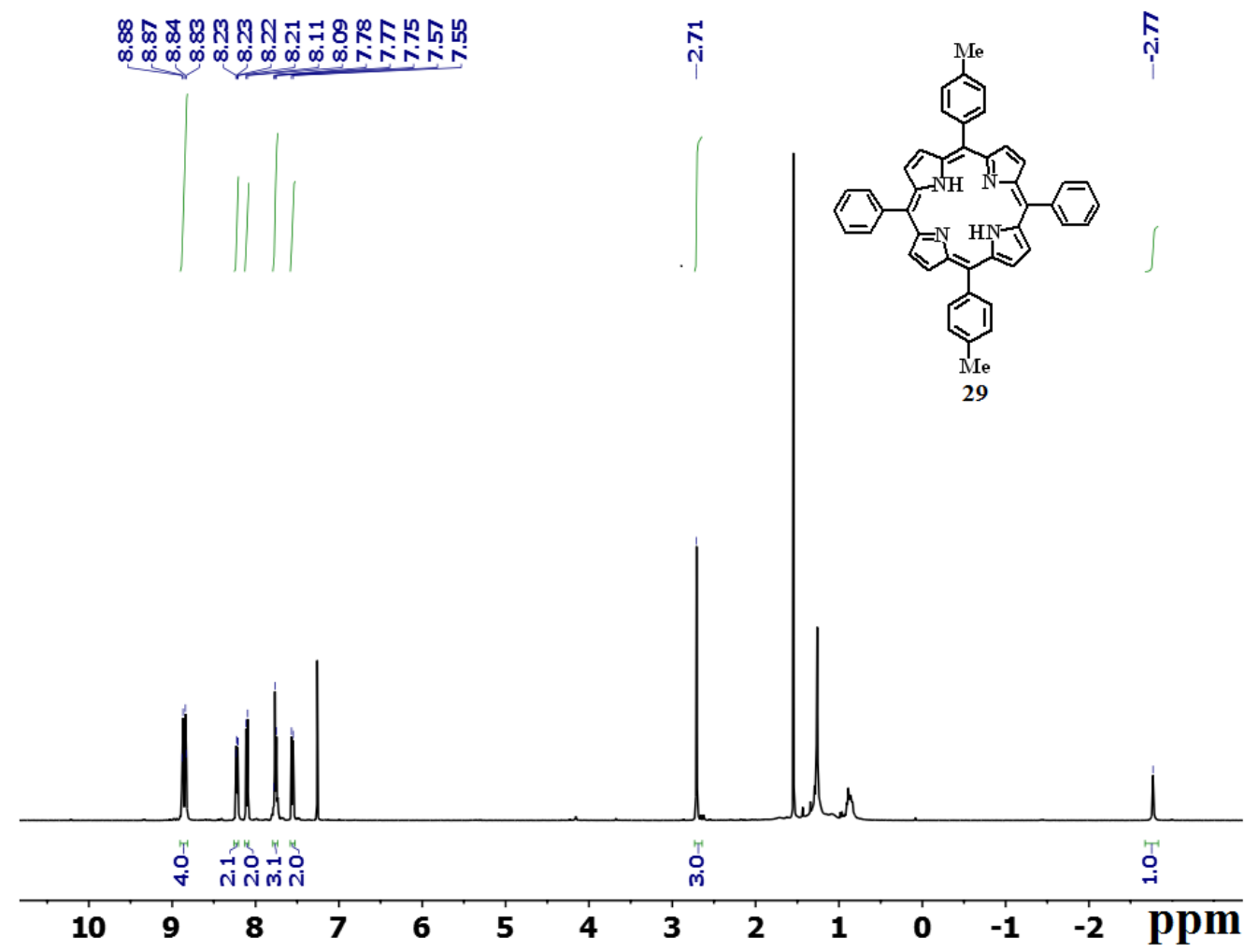

Figure S27 $\quad{ }^{1} \mathrm{H}$ NMR spectrum of 5,15-Bis(4-methylphenyl)-10,20-diphenylporphyrin, 29 in $\mathrm{CDCl}_{3}$. 


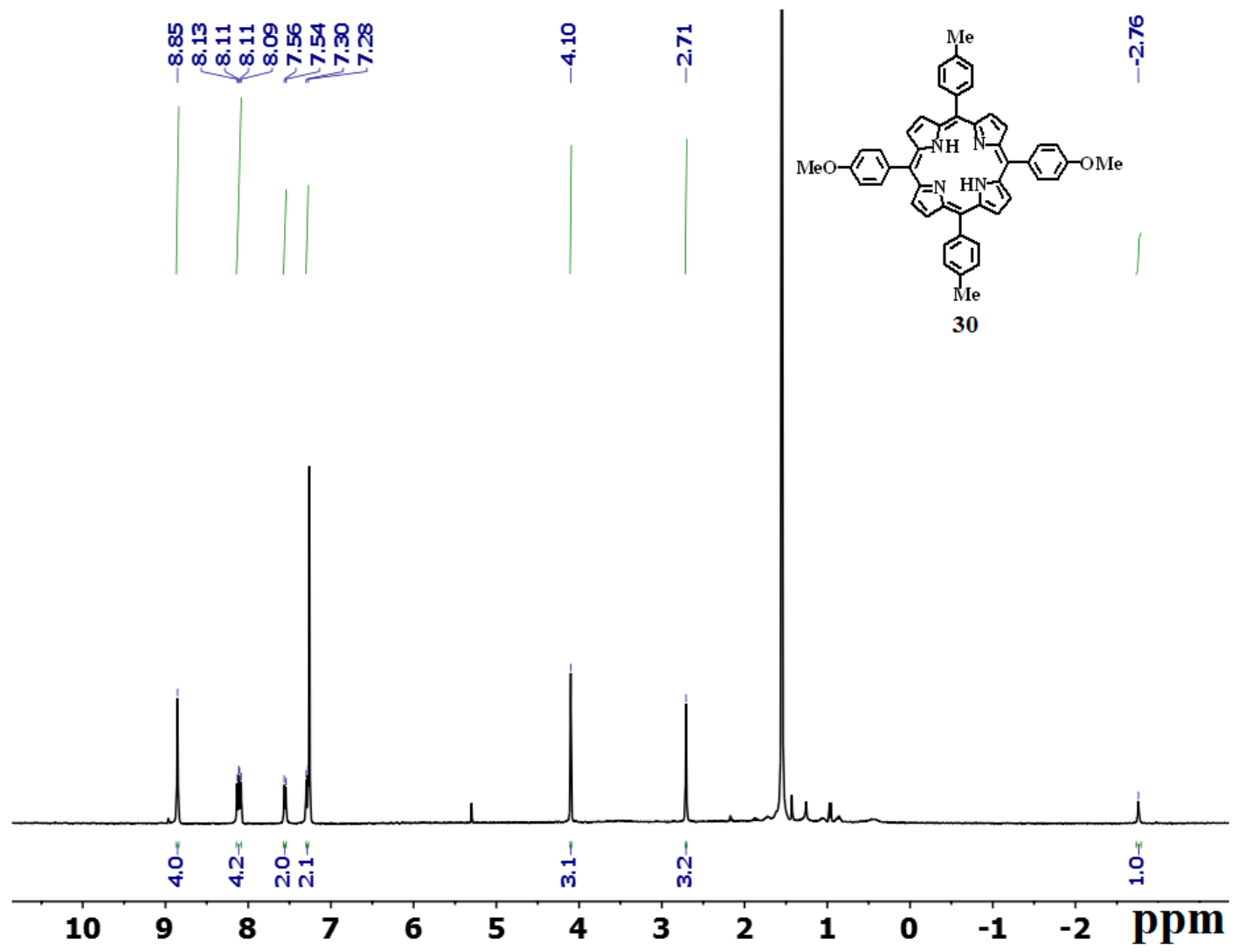

Figure S28 $\quad{ }^{1} \mathrm{H} \quad$ NMR $\quad$ spectrum of $\quad$ 5,15-Bis(4-methoxyphenyl)-10,20-(4methylphenyl)porphyrin, 30 in $\mathrm{CDCl}_{3}$. 


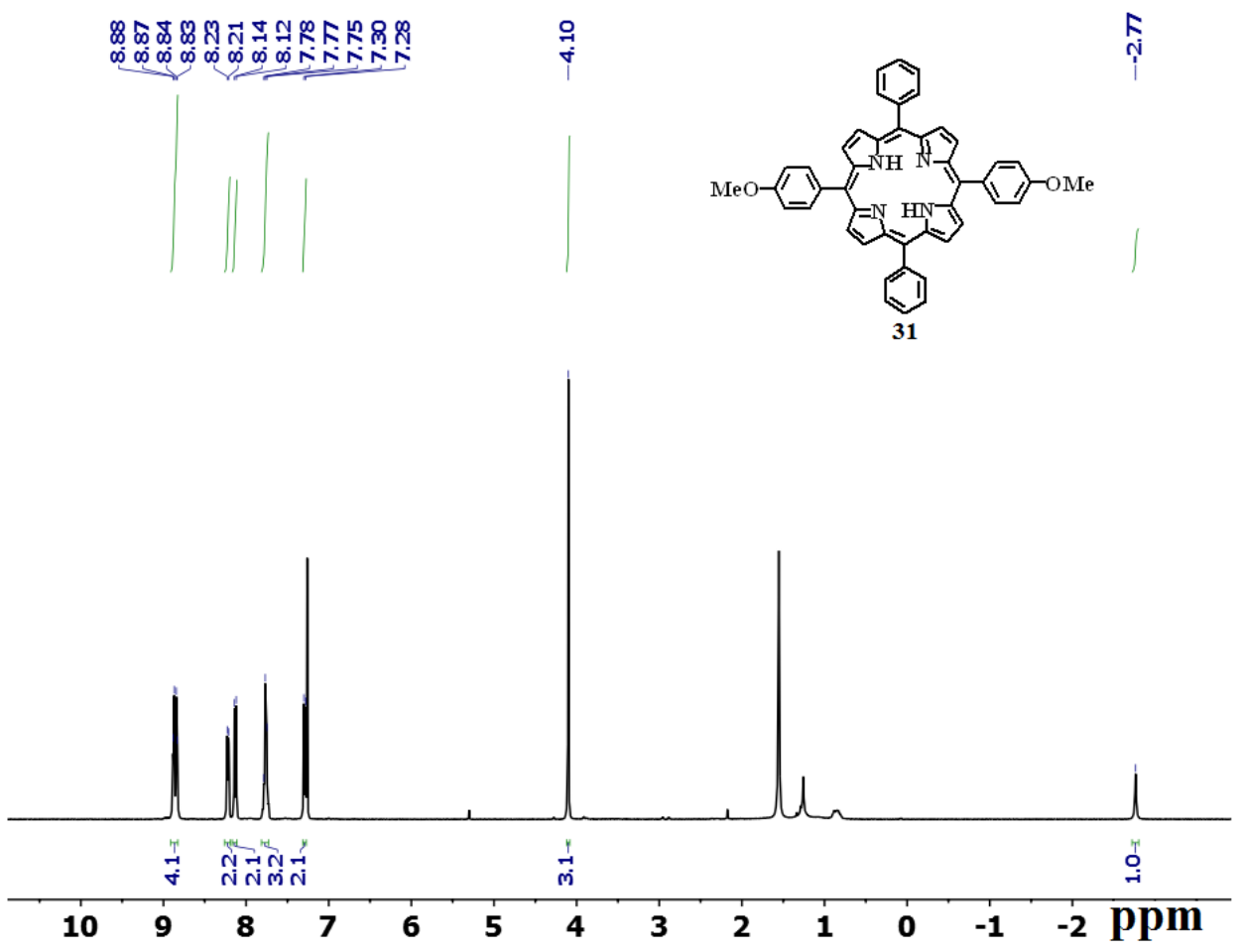

Figure S29 ${ }^{1}$ H NMR spectrum of 5,15-Bis(4-methoxyphenyl)-10,20-diphenylporphyrin, 31 in $\mathrm{CDCl}_{3}$. 


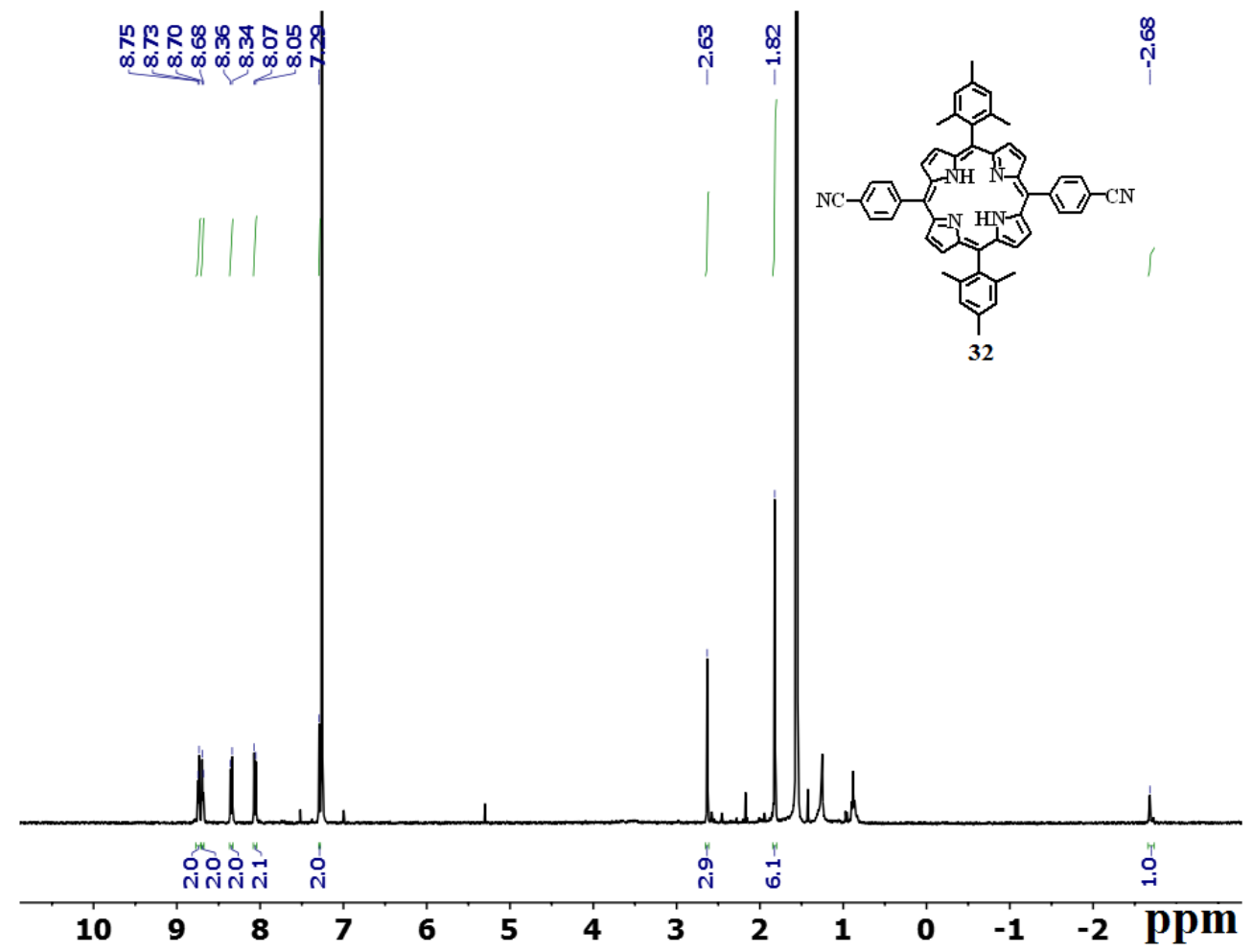

Figure S30 $\quad{ }^{1} \mathrm{H} \quad$ NMR $\quad$ spectrum of $\quad$ 5,15-bis(4-cyanophenyl)-10,20-bis(2,4,6trimethylphenyl)porphyrin, 32 in $\mathrm{CDCl}_{3}$. 


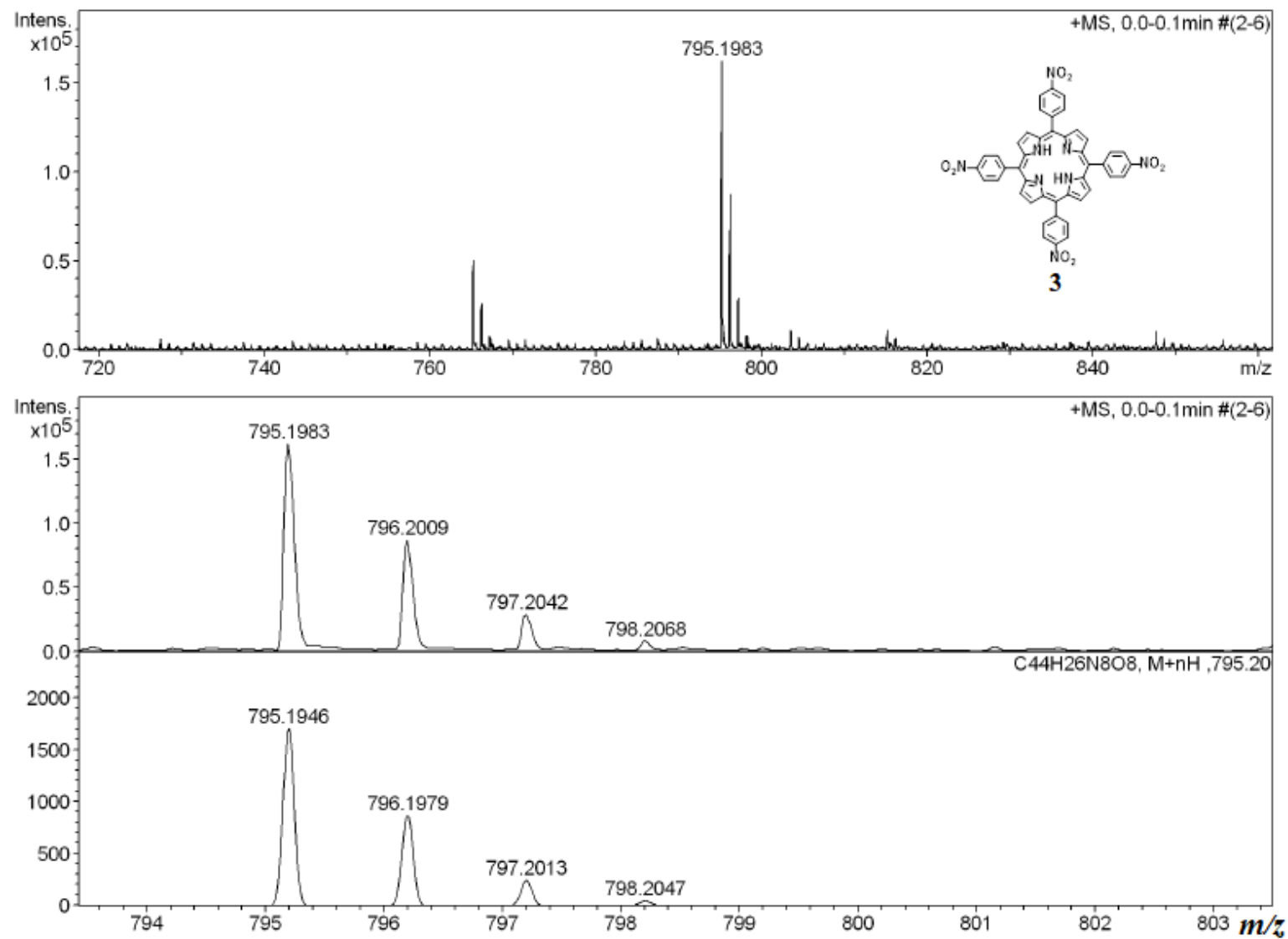

Figure S31 ESI-MS spectrum of 5,10,15,20-Tetrakis(4-nitrophenyl)porphyrin, 3 in $\mathrm{CH}_{3} \mathrm{CN}$ shows the measured spectrum with isotopic distribution pattern. 


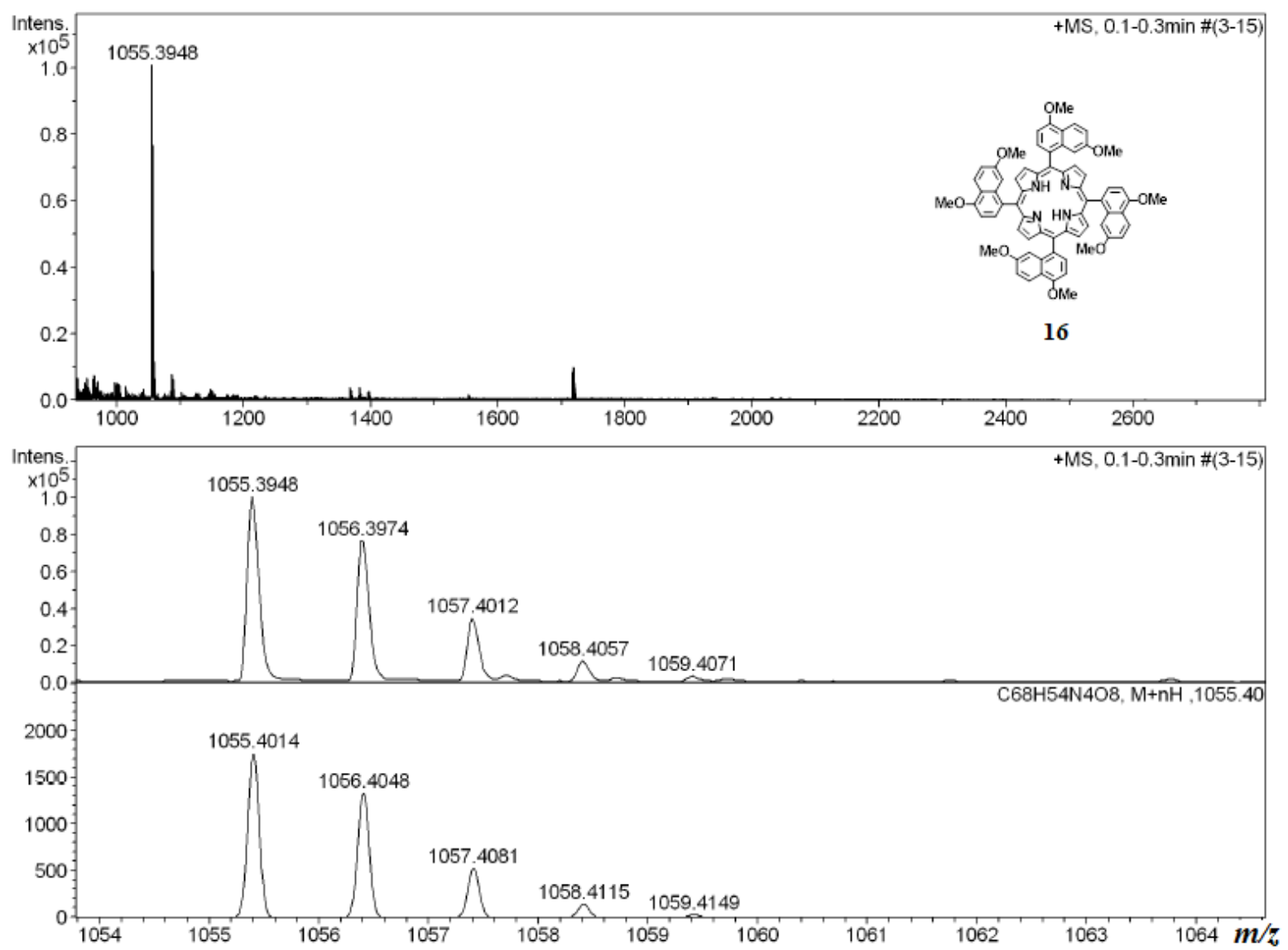

Figure S32 ESI-MS spectrum of 5,10,15,20-Tetrakis(4,7-dimethoxynaphthalen-1yl)porphyrin, 16 in $\mathrm{CH}_{3} \mathrm{CN}$ shows the measured spectrum with isotopic distribution pattern. 


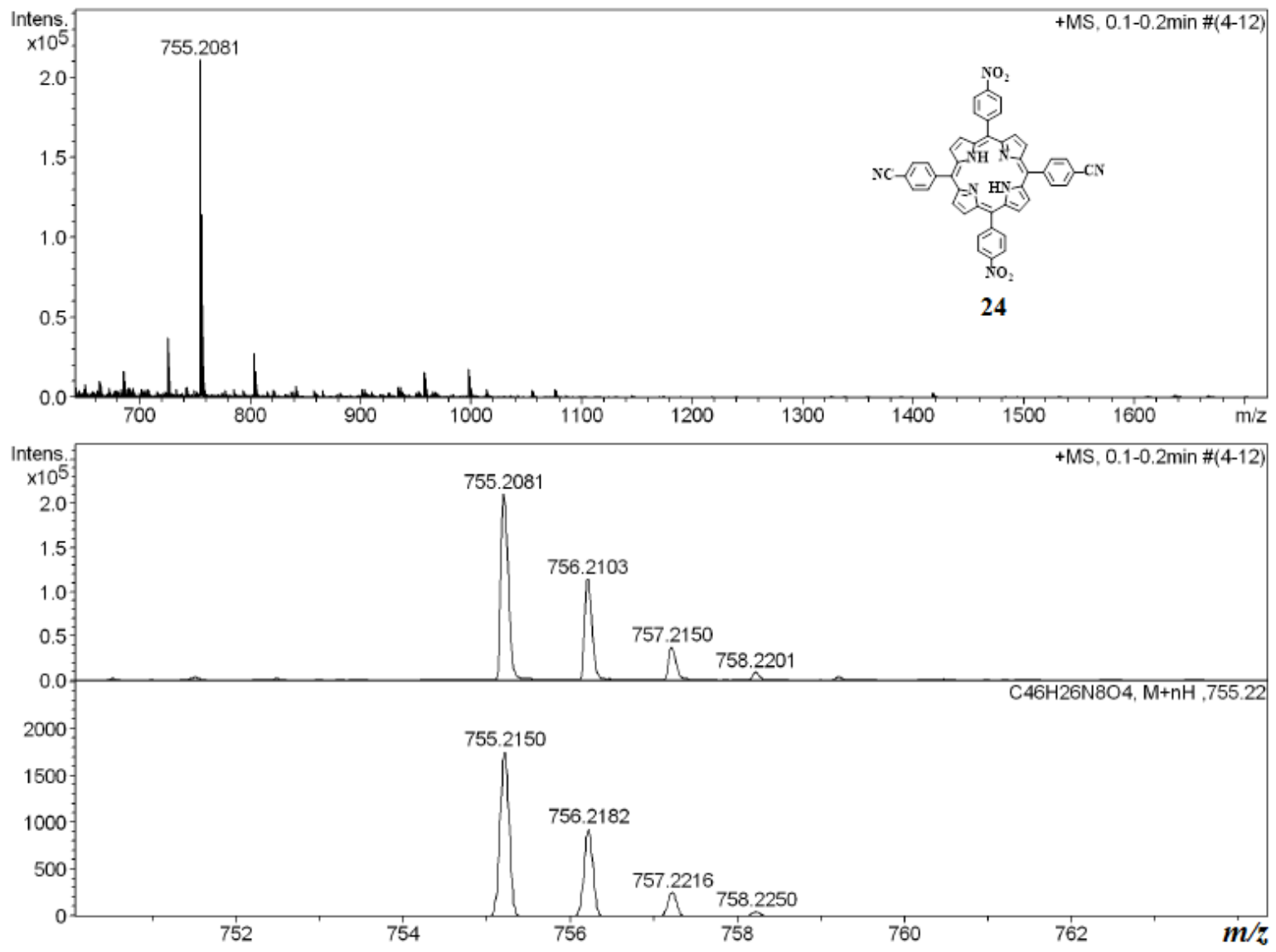

Figure S33 ESI-MS spectrum of 5,15-bis(4-cyanophenyl)-10,20-bis(4nitrophenyl)porphyrin, 24 in $\mathrm{CH}_{3} \mathrm{CN}$ shows the measured spectrum with isotopic distribution pattern. 